\title{
Factors Contributing to Record-Breaking Heat Waves over the Great Plains during the 1930s Dust Bowlo
}

\author{
Tim Cowan, Gabriele C. Hegerl, IoAna Colfescu, and Massimo Bollasina \\ School of Geosciences, University of Edinburgh, Edinburgh, United Kingdom \\ ARIAAN PURICH \\ CSIRO Oceans and Atmosphere, Aspendale, Victoria, Australia \\ GHYSLAINE BOSCHAT \\ School of Earth Science, University of Melbourne, Melbourne, Victoria, Australia
}

(Manuscript received 7 June 2016, in final form 3 October 2016)

\begin{abstract}
Record-breaking summer heat waves were experienced across the contiguous United States during the decade-long "Dust Bowl" drought in the 1930s. Using high-quality daily temperature observations, the Dust Bowl heat wave characteristics are assessed with metrics that describe variations in heat wave activity and intensity. Despite the sparser station coverage in the early record, there is robust evidence for the emergence of exceptional heat waves across the central Great Plains, the most extreme of which were preconditioned by anomalously dry springs. This is consistent with the entire twentieth-century record: summer heat waves over the Great Plains develop on average $\sim 15-20$ days earlier after anomalously dry springs, compared to summers following wet springs. Heat waves following dry springs are also significantly longer and hotter, indicative of the importance of land surface feedbacks in heat wave intensification. A distinctive anomalous continental-wide circulation pattern accompanied exceptional heat waves in the Great Plains, including those of the Dust Bowl decade. An anomalous broad surface pressure ridge straddling an upper-level blocking anticyclone over the western United States forced substantial subsidence and adiabatic warming over the Great Plains, and triggered anomalous southward warm advection over southern regions. This prolonged and amplified the heat waves over the central United States, which in turn gradually spread westward following heat wave emergence. The results imply that exceptional heat waves are preconditioned, triggered, and strengthened across the Great Plains through a combination of spring drought, upper-level continental-wide anticyclonic flow, and warm advection from the north.
\end{abstract}

\section{Introduction}

The aptly named "Dust Bowl" drought that plagued the contiguous United States during the 1930s caused widespread misfortune for many regional communities and severely dented the emerging economy. It covered almost one-third of the United States (Peterson et al. 2013), breaking all-time maximum temperature records across the Great Plains and the Mississippi basin

Supplemental information related to this paper is available at the Journals Online website: http://dx.doi.org/10.1175/ JCLI-D-16-0436.s1.

Corresponding author e-mail: Tim Cowan, tim.cowan@ed.ac.uk
(Abatzoglou and Barbero 2014; Donat et al. 2016) that still hold at the time of analysis. ${ }^{1}$ The record-breaking heat waves experienced during the Dust Bowl decade (1930-39) were not isolated incidences, but part of systematically hotter summers that emerged around 1930 across the Midwestern United States and peaked in 1936 (Cook et al. 2014; Donat et al. 2016). What triggered and subsequently amplified the Dust Bowl decade heat waves has been of great interest to the climate and hydrology communities, given the agricultural significance of the Great Plains, and the relatively smaller imposition

\footnotetext{
${ }^{1}$ As of the boreal summer of 2016, based on GHCNDEX (based on GHCN data; see Donat et al. 2013a), from http://www.climdex.org/.
} 
by greenhouse gas-induced warming in the early twentieth century. Managing the risk that heat waves pose is underscored by the fact that state-of-the-art climate models project an intensification of heat extremes across the United States and Canada in the upcoming decades and beyond (Meehl and Tebaldi 2004; Diffenbaugh and Ashfaq 2010; Grotjahn et al. 2016; Jeong et al. 2016; Teng et al. 2016), potentially exposing a greater proportion of the population to these extreme events (Jones et al. 2015), as witnessed for example in Chicago in 1995 (Livezey and Tinker 1996).

The trigger of summer heat waves and their intensification during the Dust Bowl decade is still an open question some 80 years after their occurrence. Spring precipitation deficits across the central and western United States were observed prior to the Dust Bowl summers (Cook et al. 2011; Donat et al. 2016), which contributed to the drought severity over the Great Plains and the devastating dust storms (Mattice 1935; Cook et al. 2014). Aside from significantly low summer precipitation, anomalous deficits continued through the autumn (Schubert et al. 2004a). The spring precipitation deficit limited soil moisture availability over the Great Plains (and across the Midwest and Northwest; Donat et al. 2016), reducing evapotranspiration at the surface and increasing sensible heating throughout summer, as is common in water-limited regions (Yin et al. 2014). An increase in hot extremes following precipitation deficits has been observed across much of North America and Europe (e.g., Mueller and Seneviratne 2012). This combination of dry soils and midtropospheric anticyclonic blocking has also been implicated as the causal factor behind the European mega-heat waves of 2003 and 2010 (Fischer et al. 2007a,b; Miralles et al. 2014). The extent to which dry springs play a deterministic role in the increased Great Plains summer heat wave activity and intensity has yet to be examined and quantified in the context of the Dust Bowl decade; this is the first focus of this study.

No two individual heat waves are identical, so it is possible that multiple factors lead to single or seasonally clustered events (e.g., Grotjahn et al. 2016). Isolated heat waves across the United States often develop from propagating planetary waves (Teng et al. 2013, 2016; McKinnon et al. 2016) and can be amplified downstream by strong land-atmosphere coupling (Koster et al. 2004; Fischer et al. 2007a). The spring precipitation deficits during the Dust Bowl decade were associated with a weakening in the Great Plains low-level jet (a meridional jet in the lower troposphere), preventing advection of relatively moist warm tropical air from the Gulf of Mexico and Caribbean Sea (Brönnimann et al. 2009). Additionally, midtropospheric blocking in the United
States was a common feature during the late spring and early summer months of the Dust Bowl decade, possibly amplifying the drought conditions (Cook et al. 2011). For North American heat waves, an anomalous upperlevel ridge essentially acts as a quasi-stationary blocking anticyclone that prevents synoptic-scale systems from disrupting the accumulation of heat (Lau and Nath 2012). An anomalous ridge persisted over the western United States in the spring and summer (March-July) of 1934, driving high temperature anomalies across the central Great Plains (Cook et al. 2014). Whether this ridging pattern was a systematic feature during the most extreme Great Plains heat waves is determined in the second part of this study using composite analysis.

This study differs from previous research by predominantly focusing on the Dust Bowl heat wave characteristics over the United States, in particular across the Great Plains, as opposed to only focusing on the link between summer heat and spring precipitation (Donat et al. 2016), or the relationship between decadal drought and tropical ocean conditions (e.g., Hoerling and Kumar 2003; Schubert et al. 2004b). We first provide an overview of the well-established metrics and the clustering technique used (section 2) and then quantify the Dust Bowl heat waves (sections $3 a$ and $3 b$ ). We then focus on the roles of spring drought severity (sections $3 c$ and $3 d$ ) and concurrent synoptic conditions during the earliest summer heat waves (section $3 \mathrm{~g}$ ). We also provide a cautionary note on the biases that emerge when calculating heat wave metrics using gridded reanalysis (sections $3 \mathrm{e}$ and $3 \mathrm{f}$ ). A discussion of the implications of the results is provided in section 4 . The expectation of this study is to establish the unique characteristics of heat waves over the Great Plains, and the conditions that distinguish the most exceptional events, like those witnessed during the Dust Bowl decade, to heat waves occurring amid later multiyear drought periods such as 1950s and 1980s.

\section{Data and methods}

\section{a. Observational and reanalysis data}

We utilize daily temperature data from stations networked across the United States and Canada that form part of the Global Historical Climate Network (GHCN)-Daily archive (Menne et al. 2012). The stations were either included in the United States Historical Climatology Network or nonmember stations that have passed the necessary quality assurance checks. Because so few high-quality stations exist in the early twentieth century, only stations that have daily maximum and minimum temperature ( $T_{\max }$ and $T_{\min }$, respectively) from 1920 
onward, with less than $10 \%$ missing records, are used (e.g., Abatzoglou and Barbero 2014). We focus on the period 1920-2012 to encompass other decades with anomalous heat wave activity and to allow for a large sample size when constructing composites. Fourteen quality control flags, such as failed duplicate checks and failed lagged range checks, were taken into consideration and if any of these flags were raised the station was discarded. Station data homogeneity is also an issue, given inconsistencies in $T_{\max }$ and $T_{\min }$ that are noted in the $1980 \mathrm{~s}$ due to an upgrade to electronic thermometers (Abatzoglou and Barbero 2014). Temporal inhomogeneities due to stations that are missing more than three consecutive months of measurements do not affect results (not shown). A total of 774 high-quality stations are selected from across North America, with 732 from the United States and 42 from southern Canada.

Daily precipitation observations from $796 \mathrm{GHCN}$ stations are converted to monthly values to calculate the Standardized Precipitation Index (SPI) as a means of quantifying the historical meteorological drought conditions. The SPI, developed by McKee et al. (1993), describes how many standard deviations a particular precipitation value has deviated from the long-term mean, set over a given averaging period. The monthly precipitation time series is transformed into a normal distribution using a two-parameter gamma distribution fit. We consider an averaging period of three months for the SPI. As the SPI does not capture the effects of evapotranspiration, we approximate the contribution from soil moisture with a monthly Palmer Drought Severity Index (PDSI). The PDSI is a standardized drought index, combining precipitation and potential evapotranspiration information, and is significantly correlated with observed soil moisture over a number of United States regions (Dai et al. 2004). We use a self-calibrating PDSI taken from Dai (2011), which is based on the Penman-Monteith equation for calculating evapotranspiration. ${ }^{2}$ The PDSI takes into account wind speed and humidity, and is calibrated for local

\footnotetext{
${ }^{2}$ Evapotranspiration (ET) is defined as$$
\mathrm{ET}=\frac{\Delta\left(R_{n}-G\right)+\rho_{a} c_{p}\left(e_{s}-e_{a}\right) / r_{a}}{\left[\Delta+\gamma\left(1+\frac{r_{s}}{r_{a}}\right)\right]},
$$

where $R_{n}$ is the surface net radiation flux, $G$ is the soil heat flux, $\rho_{a}$ is the mean air density at constant pressure, $c_{p}$ is specific heat of air, $\Delta$ is the slope of the saturation vapor pressure temperature relationship, $\left(e_{s}-e_{a}\right)$ is the vapor pressure deficit of air, $\gamma$ is the psychrometric constant, and $r_{s}$ and $r_{a}$ represent the bulk surface and aerodynamic resistances and so depend on roughness and wind speed. conditions making for a better comparison across North America (Dai 2011).

Gridded daily surface conditions and atmospheric circulation fields are taken from the Twentieth Century Reanalysis (20CR) version 2 c [e.g., temperature $\left(T_{\max }, T_{\min }\right)$, mean sea level pressure (MSLP), $10-\mathrm{m}$ winds, $500-\mathrm{hPa}$ geopotential height], with a T62 $\left(2^{\circ} \times 2^{\circ}\right)$ resolution (Compo et al. 2011). Near-surface horizontal temperature advection $\left(T_{\text {adv }}\right)$ is expressed as

$$
T_{\mathrm{adv}}=u\left(\frac{\partial T}{\partial x}\right)+v\left(\frac{\partial T}{\partial y}\right),
$$

where $u$ and $v$ are the $10-\mathrm{m}$ zonal and meridional winds, and $\partial T / \partial x$ and $\partial T / \partial y$ are the zonal and meridional 2-m air temperature gradients, respectively. Horizontal temperature advection is calculated daily and then averaged into months and seasons.

The ensemble average of the $20 \mathrm{CR}$ assimilation members is used, given that the spread between individual simulations in version 2 in capturing hot days averaged over the central United States is small during the 1930s (Donat et al. 2016). Soil moisture from 20CR is neglected given its unreliability over the central United States in the early twentieth century (Ferguson and Villarini 2012). Biases also exist in 20CR in representing the location and magnitude of heat maxima over the central United States during the summers of 1934 and 1936 (Donat et al. 2016). As a result, we first calculate heat wave metrics using station data, and then repeat the calculations for the 20CR daily temperatures to confirm the reliability of the gridded product for use in analyzing circulation patterns associated with selected heat waves.

\section{b. Defining heat waves}

A heat wave reflects an extended number of days when the daily $T_{\max }$ and/or $T_{\min }$ exceeds a given threshold, resulting in extremely hot days and a lack of nighttime relief (e.g., Nairn and Fawcett 2013). Here we define a heat wave event when the daily $T_{\max }$ surpasses its 90th percentile threshold for more than three consecutive days, with $T_{\min }$ exceeding its 90 th percentile threshold for at least the second and third days (i.e., after the third day it can fall below the threshold; however, the heat wave is still considered to continue if $T_{\max }$ continues to exceed its 90th percentile; Pezza et al. 2012). We use the daily 90 th percentile threshold based on a centered 15-day window (each calendar day is referenced to the seven days before and after) that shifts each day, such that there is no monthly or seasonal dependency (Perkins and Alexander 2013). The percentile is calculated from a 1920-2012 baseline. The daily percentile approach has the effect of removing biases that 
may arise from heat waves that extend over consecutive months, although similar results are found using monthly percentiles (not shown; Cowan et al. 2014). For each station or $20 \mathrm{CR}$ grid point over North America $\left(25.7^{\circ}-\right.$ $73.3^{\circ} \mathrm{N}, 144.4^{\circ}-56.3^{\circ} \mathrm{W}$ ) heat wave days are detected, and then heat wave metrics are aggregated over each calendar season [i.e., winter: December-February (DJF), spring: March-May (MAM), summer: June-August (JJA), and autumn: September-November (SON)]. Here DJF refers to the winter prior to the heat wave summer (i.e., previous year's December).

We quantify five main heat wave metrics:

1) HWN: the total number of heat waves (events per season);

2) HWF: the frequency of heat wave days (total number of days per season);

3) HWD: the duration of the longest heat wave (days);

4) HWA: the amplitude of the hottest seasonal heat wave (anomaly of the hottest day of the hottest seasonal heat wave, ${ }^{\circ} \mathrm{C}$ ); and

5) HWT: the timing of either the earliest, longest or hottest seasonal heat wave (summer is referenced to 1 June).

Unless specified otherwise, we refer to heat waves as summer events only. A further test was also carried out to determine if possible contamination between closely occurring heat waves [less than 15 days between events, as in Teng et al. (2016)] might lead to event count biases. The test showed that there is little difference between the decadal averages of heat wave metrics when events are separated by at least 15 days and those with no separation, aside from a broad-scale reduction in HWN and HWF (since fewer events are considered; not shown). Therefore, we consider all possible heat wave days, but we acknowledge the possibility of overestimating the total number of independent events and underestimating the longest summer event.

The heat wave metrics are calculated for the 774 GHCN stations and for North American grid points for 20CR, although we predominantly focus on three key Dust Bowl drought regions: the northern Great Plains $\left(40^{\circ}-50^{\circ} \mathrm{N}, 105^{\circ}-85^{\circ} \mathrm{W}\right.$; temperate climate), the southern Great Plains $\left(30^{\circ}-40^{\circ} \mathrm{N}, 105^{\circ}-85^{\circ} \mathrm{W}\right.$; subtropical climate) and the combined region (termed simply the Great Plains). The Great Plains here is identical to that area that has recorded a high number of hot days during the 1930s (Donat et al. 2016). When a station or grid point detects no seasonal heat wave activity then HWN and HWF are set to zero, whereas HWD, HWA, and HWT are set to missing values. For decadal averages of HWD, HWA, and HWT (as in Fig. 2), we require that the temporal coverage of heat wave data in question for a given point must be greater than $50 \%$ (i.e., more than five years out of a decade must have heat waves detected). This prevents small sample sizes from skewing decadal averages. To address geographical biases when spatially averaging stations over a given region, stations are clustered into $2^{\circ} \times 2^{\circ}$ grids and areal averaged over that region [similar to Abatzoglou and Barbero (2014), who averaged over a $1^{\circ}$ horizontal resolution]. The heat wave metrics are always calculated for each station prior to averaging over each region, as opposed to averaging temperatures first, given the areal extent of the regions.

Statistical significance of summer heat wave composites ranked by the anomalously dry or wet springs is assessed using a Wilcoxon sign-ranked test (Hollander and Wolfe 1999). This nonparametric test determines if two samples are distinguishable from each other at the $90 \%$ confidence level, based on the difference between the means of two sets of cases consisting of the 10 wettest and driest springs over a predefined region. The null hypothesis of this test is that the median difference between the composites is zero. Similar testing was carried out on the SPI-based composites using a Mann-Whitney $U$ test and the results were very similar (not shown). ${ }^{3}$ The significance is indicated on the spatial maps comparing the heat wave metric composites. For composites that are averaged both spatially and temporally, we perform a Monte Carlo test where the significance between wet and dry spring cases is assessed by generating 1000 sets of 10 randomly sampled summers. Likewise, for circulation and surface condition composites associated with heat waves using $20 \mathrm{CR}$ (i.e., Fig. 11 onward), the significance is tested by generating 1000 null composites comprising randomly resampled summers, using identical sample sizes to that of each region's composite. A two-tailed $t$ test is used to determine if a grid cell is significant at the $95 \%$ level based on whether that cell's value is greater or less than its equivalent cell in 975 out of the 1000 null composites.

\section{c. Temporal aggregation of heat waves}

By temporally aggregating heat waves (by date) we can assess the average circulation associated with heat waves on a week to week time frame. For this we only focus on the synoptic conditions of the earliest summer events. This avoids contamination of synoptic patterns associated with frequently recurring heat waves. We perform a temporal aggregation technique whereby the

\footnotetext{
${ }^{3}$ The Mann-Whitney $U$ test was not considered for the PDSI composite years given the partial dependence of PDSI and heat wave metrics (i.e., they both contain temperature in their definition), although we compare spring drying with summer heat waves.
} 
earliest summer heat wave that occurs at each GHCN station is assigned a start date. All stations over the Great Plains are analyzed and the total number of GHCN stations for each summer day is counted and grouped together to form a unique station date index. We then calculate the cumulative sum of stations for each day that record a heat wave start until a threshold percentage of stations across the region of interest is exceeded. To capture the early summer atmospheric circulation conditions, the threshold of counted stations is arbitrarily set to $10 \%$. For example, in 1934, 323 stations within the Great Plains registered at least one heat wave; we select the date when more than 32 stations (10\%) have recorded a heat wave start, which, for 1934 , is 5 June. This date differs in each summer depending on how many stations observe heat wave activity (see Fig. S9 in the online supplemental material) or the region of interest (i.e., northern, southern, or entire Great Plains). The $10 \%$ threshold captures the synoptic conditions both prior to and after the earliest summer heat wave, instead of secondary and tertiary heat waves that may emerge from the recurring circulation patterns (i.e., blocking anticyclones), as could happen by increasing the station count threshold to above $10 \%$ (see Fig. S12). We have performed sensitivity tests by lowering the threshold to $5 \%$ to capture very early heat wave conditions; however, this produces very similar results to the $10 \%$ threshold case (not shown).

Three distinct week-long phases are chosen over which the atmospheric and surface conditions are averaged around the earliest heat wave start date of the summer, based on the $10 \%$ GHCN station exceedance level:

1) Week - 1: 1-7 days prior to the heat wave commencing (e.g., for 1934, this is 29 May-4 June);

2) Week 1: 1-7 days after the heat wave start (e.g., for 1934 , this is 6-12 June); and

3) Week 2: 8-14 days after the heat wave start (e.g., for 1934 , this is 13-19 June).

\section{Results}

\section{a. Dust Bowl decade heat waves}

Many of North America's highest daily $T_{\max }$ and $T_{\min }$ (TXX and TXn) records were set in the 1930s and 1940s, with extremes spanning the southeast United States through to northwest Canada (Figs. 1a,b). The 1930s decade holds the record for the hottest $T_{\max }$ and $T_{\min }$ decade averaged over the central United States (boxed region in Fig. 1 a covering $30^{\circ}-50^{\circ} \mathrm{N}, 105^{\circ}-85^{\circ} \mathrm{W}$, referred to as the Great Plains), exceeding the second and third warmest decades (1910-19 and 1940-49, respectively) by $\sim 1.5^{\circ} \mathrm{C}$ (Fig. 1c). The summer of 1936 is the most common record-breaking year for the hottest temperatures over the Great Plains, although records also fell in the early 1930s across the southwest and southeast United States (Figs. 1a,b). As many North American extreme temperature records were set prior to the 1950s, a decrease in extreme temperatures (i.e., TXx and TXn) has been observed since the 1930s (Fig. 1c). Despite a decline in the frequency of hot days since the 1950s (Morak et al. 2013), summer heat wave and winter warm spell frequency have increased across the western United States and central-western Canada since this decade (Perkins et al. 2012).

Along with record temperatures, the Great Plains experienced the highest number of summer heat wave days (HWF) in the 1930s of any decade post-1920 (up to and including 2012; Fig. 2a; the post-1960 decades are shown in Fig. S1). Many Great Plains stations exceeded 10 heat wave days per summer averaged over the Dust Bowl decade ( $\sim 2$ events per summer on average), with maximum heat wave durations (HWD) $>7$ days and temperature anomalies (HWA) $>10^{\circ} \mathrm{C}$, particularly in the northern Great Plains (Figs. 2b and 2c, respectively). Even the average length of the heat waves (i.e., the ratio of HWF to HWN, as opposed to HWD) was greater in the 1930s, with a greater proportion of stations across North America (51.4\%) with average event lengths $>5$ days on average, compared to the 1940 s and $1950 \mathrm{~s}$ (28.2\% and $37.9 \%$, respectively; figure not shown). The prominent meridional gradient in HWA that increases with latitude is due to the smaller diurnal and seasonal variability in the subtropical climate of the southern United States (Perkins and Alexander 2013); the same feature is captured in the average heat wave temperature (not shown). In the 1940s, the northern Great Plains still experienced more than 7 heat wave days per summer, despite the anomalously wet conditions early in the decade (Brönnimann et al. 2009). The southern Great Plains experienced more than 10 heat wave days per summer on average in the 1950s with HWD exceeding 9 days, which coincided with a protracted drought over the southern United States (Cook et al. 2011). Heat wave activity rose again in the 1980s across the central eastern United States, dropped off in the 1990s, and then increased again in the 2000s, predominantly in the southern regions (Fig. S1). It is worth recalling that the decadal averages only include stations with at least $50 \%$ temporal coverage. When all stations with at least one heat wave per decade are included (with HWD and HWA set to zero for summers with no heat waves), the 1930 s peak in heat wave activity is more prominent than for later decades (Fig. S2). Including stations with less than 50\% coverage per decade tends to amplify the signal-to-noise ratio of the heat waves; however, for the remainder of the 
(a) TXX

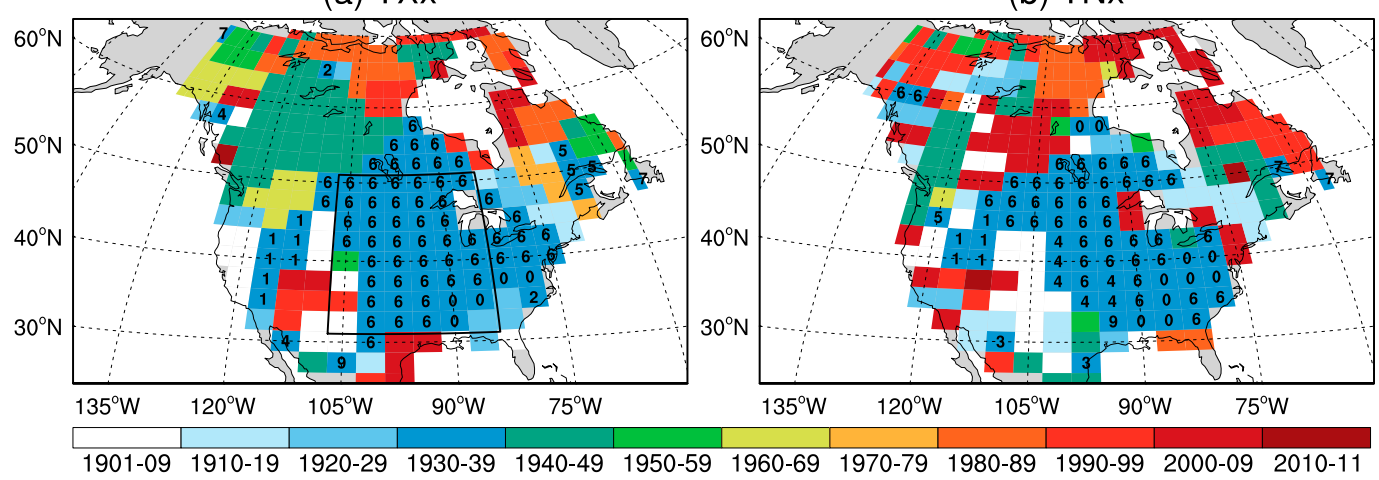

(c) Average over Great Plains

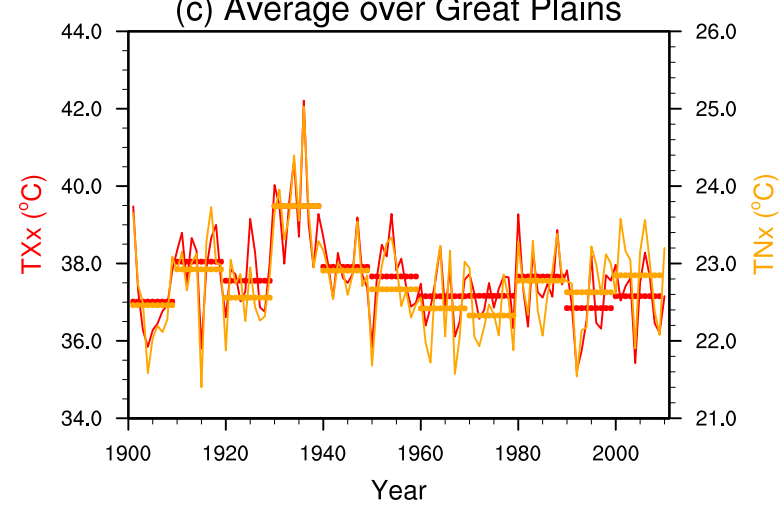

FIG. 1. Decades where the (a) highest daily maximum temperature (TXx) and (b) highest daily minimum temperature (TNx) occurred across North America over 1901-2010. (c) Average TXx (thin red) and TNx (thin orange) over the Great Plains region of North America $\left[30^{\circ}-50^{\circ} \mathrm{N}, 105^{\circ}-85^{\circ} \mathrm{W}\right.$; box in (a)]. In (a) and (b), the singledigit numbers indicate the record years that occurred in the 1930s (i.e., 0 represents 1930, 4 represents 1934). In (c), the thick lines indicate decadal averages. Note that the vertical axis scales for TXx and TNx are different. Extreme temperature records are taken from the HadEX2 dataset calculated for the CLIMDEX (Datasets for Indices of Climate Extremes) project (Donat et al. 2013b).

paper we choose to only show decadal averages for stations with the $50 \%$ temporal coverage to prevent giving equal weight to decades with too few heat waves.

\section{b. Interseasonal variations in Dust Bowl heat waves}

Next we investigate the interannual and interseasonal variations of HWD during the most prominent heat wave years in the 1930s (1930-37). HWD is selected here, as the longest heat waves are often the hottest (HWA) and are a strong determinant in the total number of heat wave days (HWF; this is shown in Fig. S3). The correlation coefficient of HWD with HWA (HWF) for summer averaged over the Great Plains is $0.68(0.89)$. Given that heat extremes are not just restricted to summer (Perkins and Alexander 2013), we also focus on spring and winter warm spells. Figure 3 (Fig. S3) highlights the interseasonal HWD (HWF) variations over 1930-37 from winter to summer. Large variations in HWD appear throughout the 1930s; for example, prior to the summer of 1934 protracted winter warm spells and spring events impacted the western United States and northern Great Plains (Fig. 3, fifth row). Similarly, the Great Plains experienced extensive winter warm spells in 1930 and 1931 exceeding 8 days (Fig. 3a, first and second row), coinciding with the 1930/31 central Pacific El Niño event. Central Pacific El Niños are associated with winter precipitation deficits across the central eastern United States, through the equatorward displacement of the tropospheric jet and winter storms (Yu and Zou 2013). Although warm spell activity fell in the spring of 1931 (Fig. 3b and Fig. S3b, second row), drought conditions persisted over the Great Plains (Figs. 4d,e). Heat wave activity rebounded in the summer of 1931 (Fig. 3c, second row), extending into the autumn (not shown) and winter of 1931/32, particularly over the eastern United States, where HWF exceeded 20 days (Fig. S3a, third row). In general, aside from 1934 and 1936 we see a tendency for warm spell activity to drop in the spring (from winter), followed by a heat wave activity increase in summer. 


\section{(a) HWF}

(b) HWD

(c) HWA
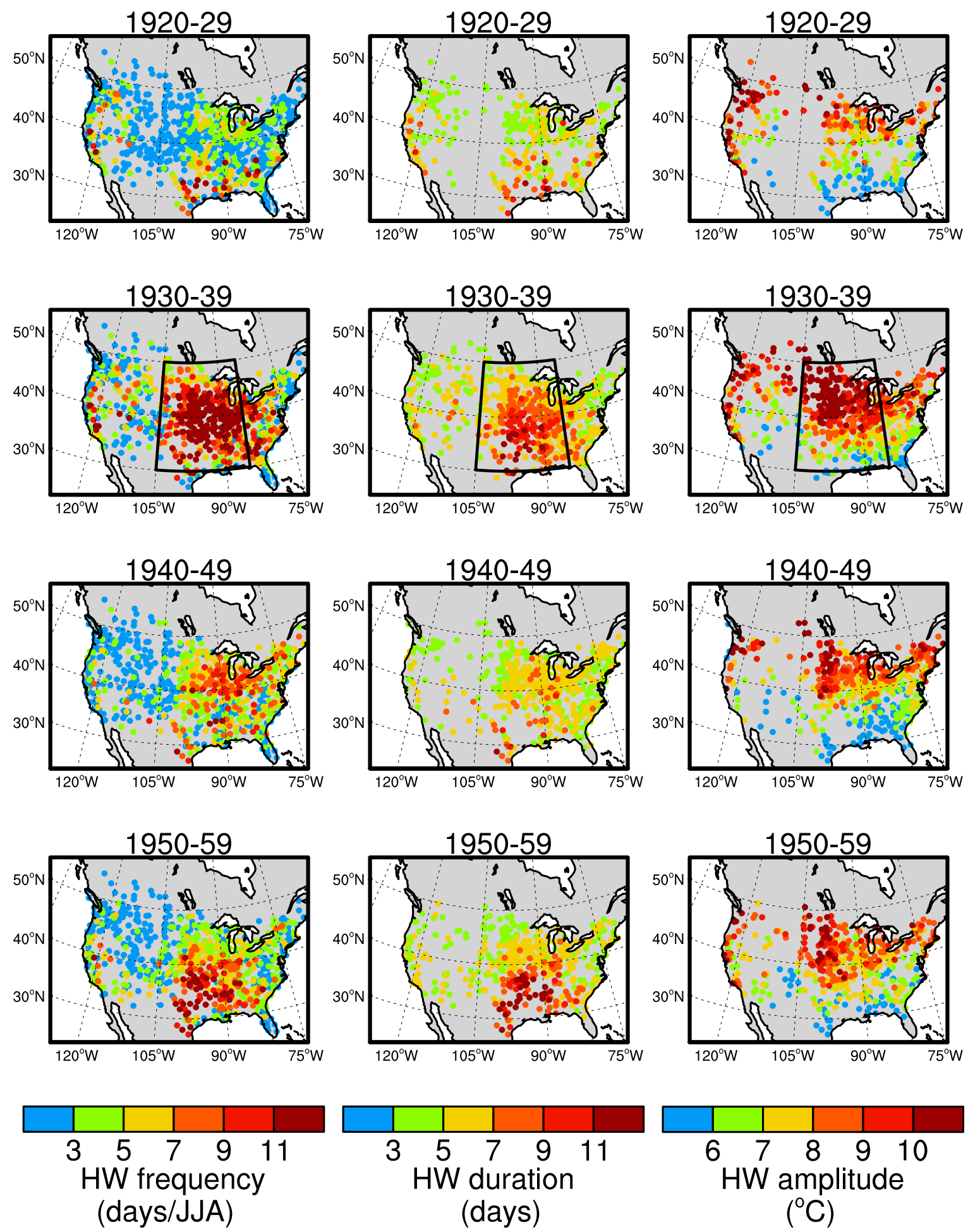

FIG. 2. Decadal averages of summer heat wave (a) frequency (HWF), (b) duration (HWD), and (c) amplitude (HWA) for GHCN-daily station observations over 1920-59. The decades over 1960-2012 are shown in Fig. S1. For HWD and HWA, only stations with more than $50 \%$ temporal coverage (i.e., summers with heat waves) for individual decades are shown. The box in the second row represents the Great Plains region, where the Dust Bowl heat wave activity was most severe. 


\section{(a) DJF \\ (b) MAM \\ (c) JJA}
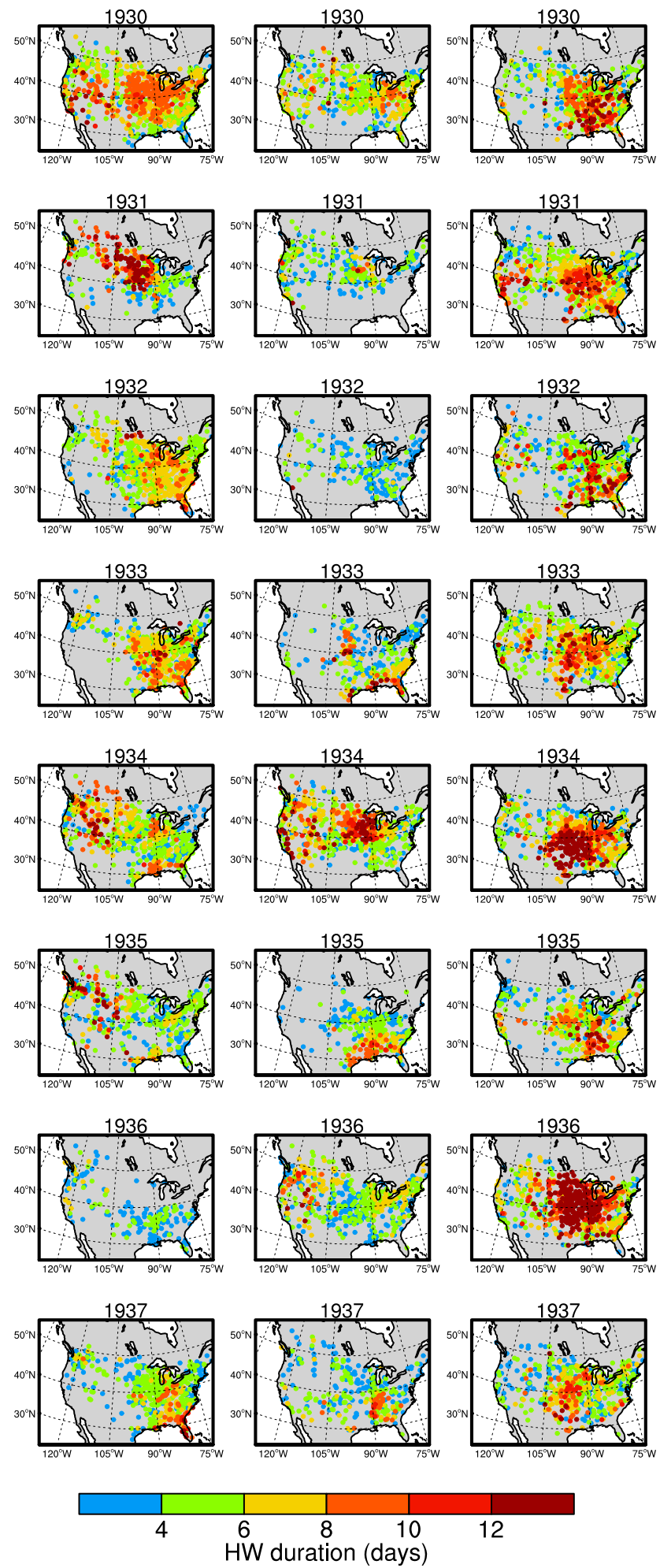

FIG. 3. Seasonal HWD over 1930-37 (i.e., most dominant heat wave seasons in the 1930s): (a) DJF, (b) MAM, and (c) JJA. The sparsity of colored dots reflects the lack of heat wave activity in individual seasons. The equivalent for HWF is shown in Fig. S3. 


\section{Great Plains}

(a) $\overline{\mathrm{HWN}}$

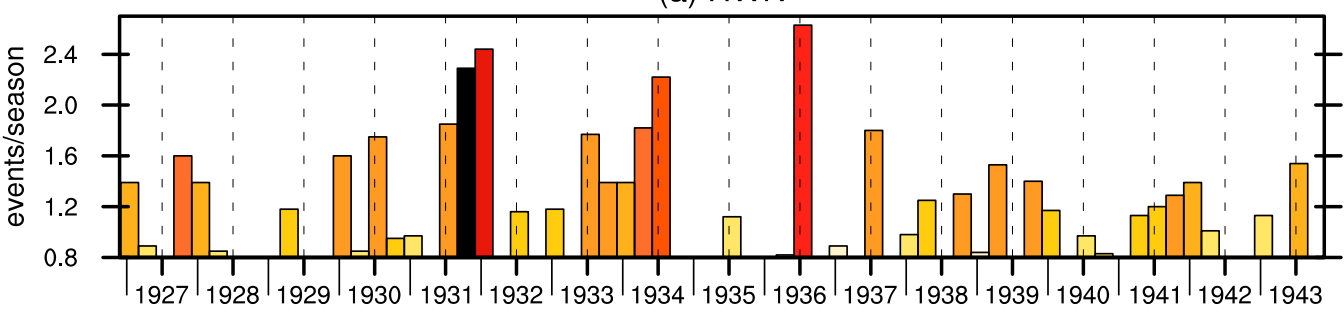

(b) $\overline{\mathrm{HWD}}$

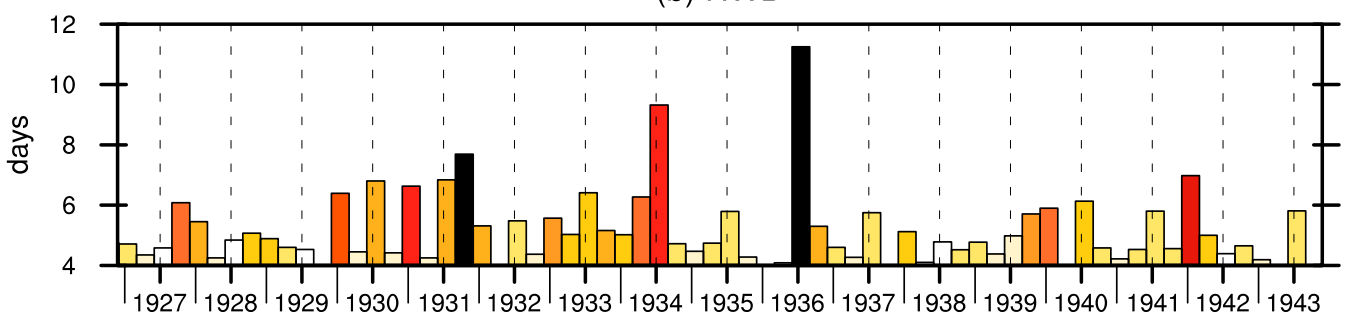

(c) HWA

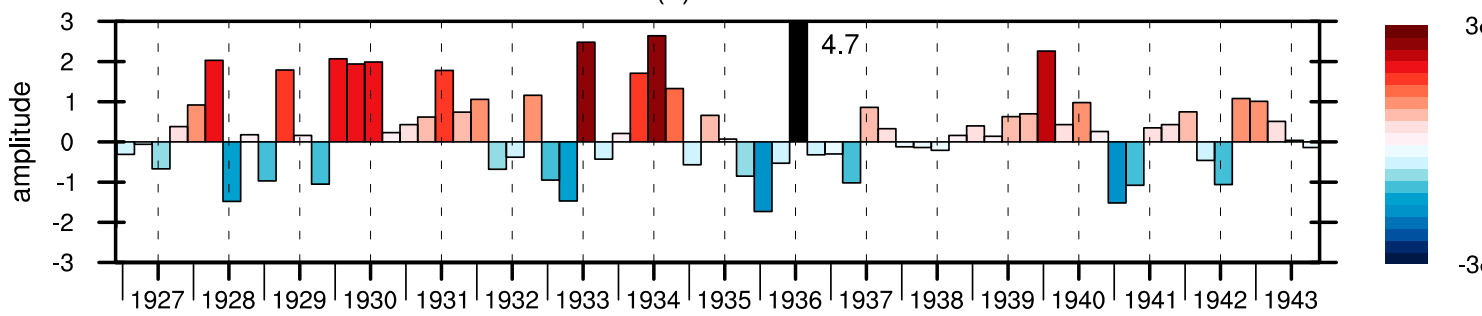

(d) $\overline{\mathrm{SPI}}$

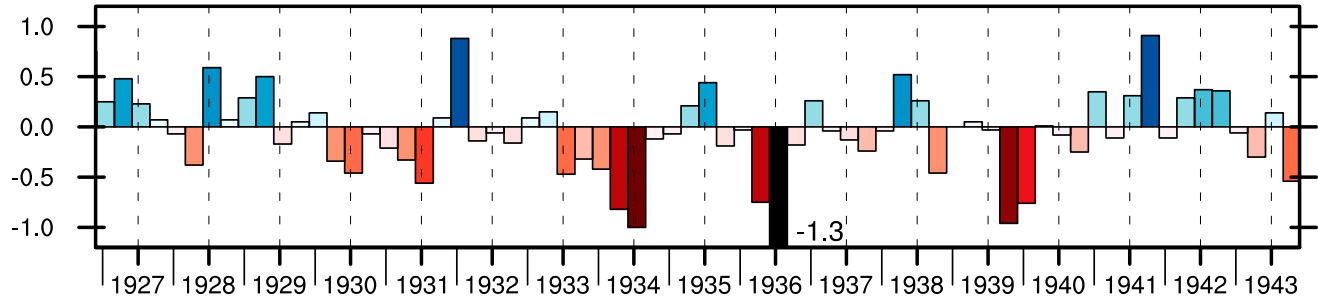

$3 \sigma$

(e) $\overline{\text { PDSI }}$

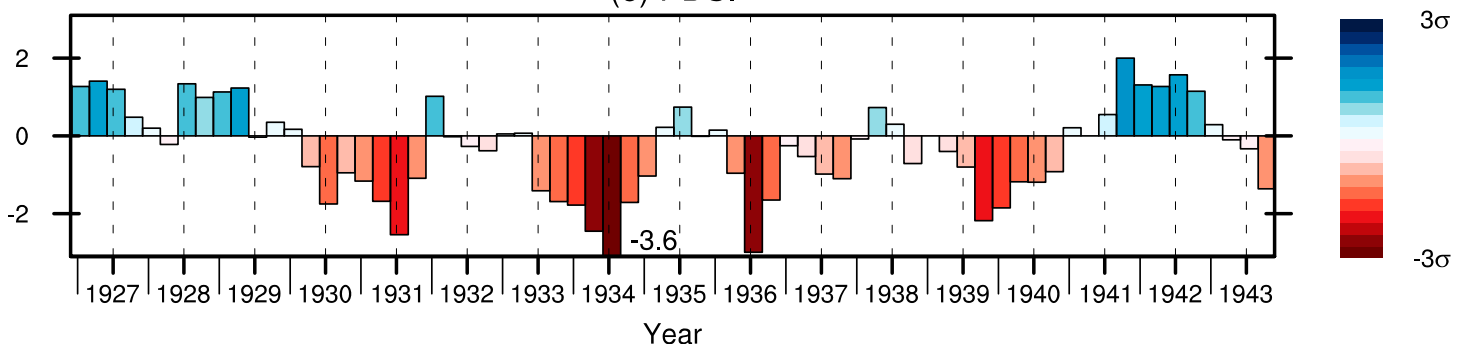

FIG. 4. Heat wave and drought metrics averaged across the Great Plains over 1927-43 for each season: (a) $\overline{\mathrm{HWN}}$, (b) $\overline{\mathrm{HWD}}$, (c) $\overline{\mathrm{HWA}}$,

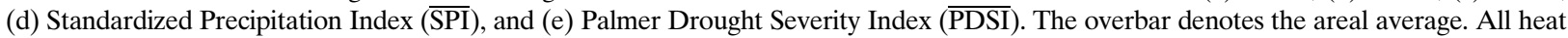
wave metrics are calculated from station temperatures, with HWA standardized for each season to assist in comparisons. The SPI is calculated from station precipitation over three months and then aggregated into seasons and the $\overline{\text { PDSI }}$ is based on the self-calibrating index of Dai (2011). The right-hand side color bars represent the number of standard deviations $(\sigma)$ each value reaches (from the mean for $\overline{\mathrm{HWN}}$ and $\overline{\mathrm{HWD}}$ ) based on seasonal aggregation. The darker colors represent more extreme values, while the values adjacent the vertical black bars indicate the most extreme summer index values that surpass the vertical axis limit. The vertical dashed lines indicate each summer. 
The interseasonal variations in HWN, HWD, HWA and two drought indices (SPI and $\mathrm{PDSI}^{4}$ ), areal averaged over the Great Plains during the 1930s (indicated by the overbar), are shown in Fig. 4. Interseasonal variations averaged over the northern and southern Great Plains separately are shown in Fig. S4. We also highlight the interseasonal variations of the heat wave metrics and drought indices over the Great Plains from 1979 to 2012 as a way of placing the Dust Bowl conditions in the context of recent conditions (Fig. 5). Summer of 1936 emerged as the season with the most frequent and protracted heat waves, where HWN and HWD exceeded 2.5 events $(\sim 4 \sigma)$ and 11 days (above $4 \sigma)$, respectively (Figs. 4a,b). HWA, standardized to facilitate seasonal comparison, exceeded $4 \sigma$ in 1936, around twice the peak of 1934. Furthermore, five out of the six hottest Great Plains heat waves from 1920 to 2012 occurred in the 1930s $(1930,1931,1933,1934,1936){ }^{5}$

Dry springs were a common feature shared between four $(1930,1931,1934,1936)$ of the hottest heat wave summers (Figs. 4d,e), although the springs of 1931 and 1934 were preceded by more than three anomalously dry seasons (i.e., carried through from the previous year). Average SPI values $\leq-1$ and PDSI values $\leq-3$ preceded the intense summers of 1934 and 1936 (Figs. 4d,e); for PDSI, this is classified as extreme drought (Dai 2011). Yet, despite 1936 being the third driest spring on record for the Great Plains (based on SPI, although 1936 was the driest spring on record if considering precipitation alone; Donat et al. 2016), and the driest on record over the southern Great Plains (Fig. S4i, Table 1), spring warm spell activity was relatively low (Figs. 4a-c). Across the northern Great Plains, from the summer of 1929 to 1941, only five seasons recorded above zero PDSI values (Fig. S4e), indicative of a decade of protracted drought. More widely, almost $75 \%$ of United States GHCN stations with the highest $T_{\max }$ records during the 1930s recorded PDSI values $\leq-3$, and around $25 \%$ of these records were set in 1936 (Abatzoglou and Barbero 2014).

In the more recent period (1979-2012), the lack of decade-long droughts is immediately apparent, as measured by the SPI (Fig. 5d). The PDSI captures a protracted drought sequence in 1988/89, associated with a switch from El Niño to a strong La Niña event in the equatorial eastern Pacific. In the summer of 1988 HWN almost reaches two events, with a HWD of 6 days and

\footnotetext{
${ }^{4}$ These indices are indicators of soil moisture conditions (e.g., Dai et al. 2004), used to assess how drought severity influences heat waves, instead of soil moisture from gridded reanalysis (Ferguson and Villarini 2012).

${ }^{5}$ The other summer is 1988 , which is the fifth hottest following 1936, 1934, 1933, and 1930.
}

HWA of $\sim 2 \sigma$. That summer aside, in general there is very little overlap between the severity and frequency of events in the later decades, with summers following dry periods like 1980, 2011, and 2012 showing relatively large HWN and HWD values $(\geq 1.3$ events, $\geq 6$ days long) but modest HWA $(\leq 0.8 \sigma)$. Therefore, clearly the Dust Bowl decade heat waves were not only more frequent and longer, but substantially hotter than events at the turn of the twenty-first century. The Dust Bowl heat waves were also broader in their spatial extent of impact (Fig. 2), and emerged during extended periods $(5+\mathrm{yr})$ of drought.

\section{c. Dry springs and heat wave activity}

It has been well established that soil moisture, often represented by proxies such as the SPI, and heat wave intensity are strongly coupled in many water-limited regions (Mueller and Seneviratne 2012), including Australia (Perkins et al. 2015), Europe (Miralles et al. 2014; Fischer et al. 2007a,b), and the United States (Donat et al. 2016). To quantify the impact of preceding dry spring conditions on heat wave activity we utilize the SPI and PDSI. Two composites are formed each consisting of summers that follow the 10 driest and 10 wettest springs (MAM) over 1920-2012. These are termed the dry-spring and wet-spring composites, respectively, with springs ranked separately by the SPI and PDSI averaged over the entire Great Plains, and over the northern and southern regions separately (see Table 1). By selecting the far tails of the distribution we test whether antecedent soil moisture leading up to summer, as represented by the lowest ranked SPI and PDSI values, is crucial in determining longer and more severe heat waves, or possibly earlier event emergence.

A spatial comparison of HWN, HWD, and HWA (variations in HWN and HWD are similar to HWF and thus it is excluded here) between the dry- and wet-spring composites is shown in Fig. 6 for the SPI rankings, given the possible temperature dependency between the summer heat wave metrics and the spring PDSI (results based on the PDSI are shown in Figs. S5 and S6). The heat wave differences following dry and wet springs averaged over the Great Plains is shown in Fig. 7, with a regional separation into the northern Great Plains and southern Great Plains shown in Fig. S7. A comparison for HWT with events separated into three classes-the earliest, longest, and hottest heat waves-is shown in Fig. 8.

On average, following an exceptionally dry spring, the majority of Great Plains stations exhibit substantially more heat waves ( $\geq 1.5$ events), as well as longer ( $\geq 7$ days) and hotter events $\left(\geq 8^{\circ} \mathrm{C}\right)$, compared to those after wet springs (Figs. 6a-c). Many stations across the southern Great Plains show significant differences (according to a 


\section{Great Plains (1979-2012)}

(a) $\overline{H W N}$

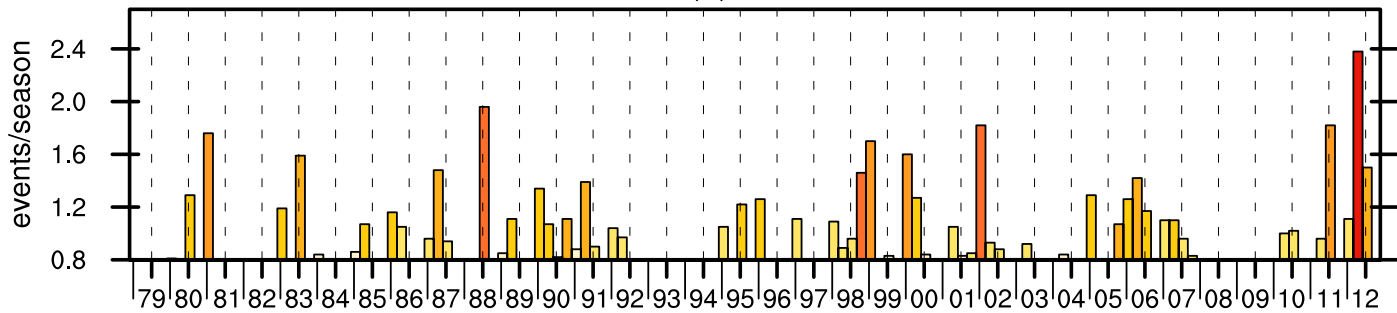

(b) $\overline{\mathrm{HWD}}$

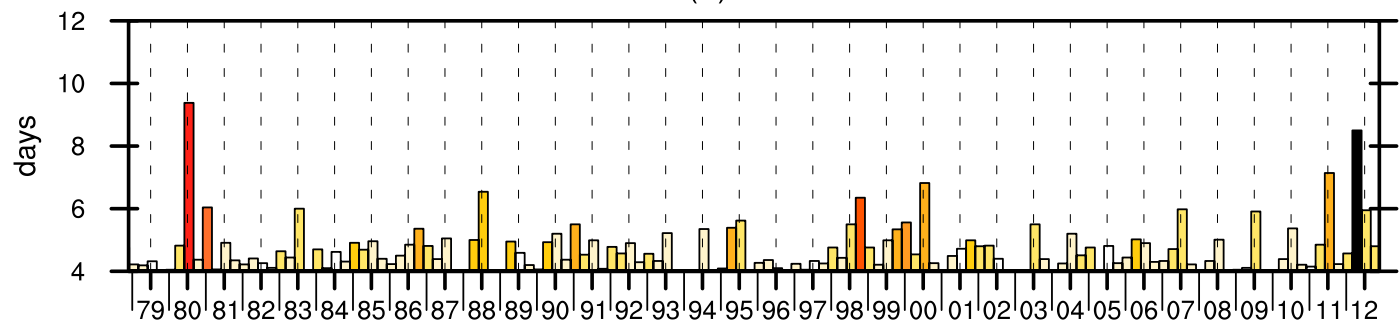

(c) $\overline{H W A}$

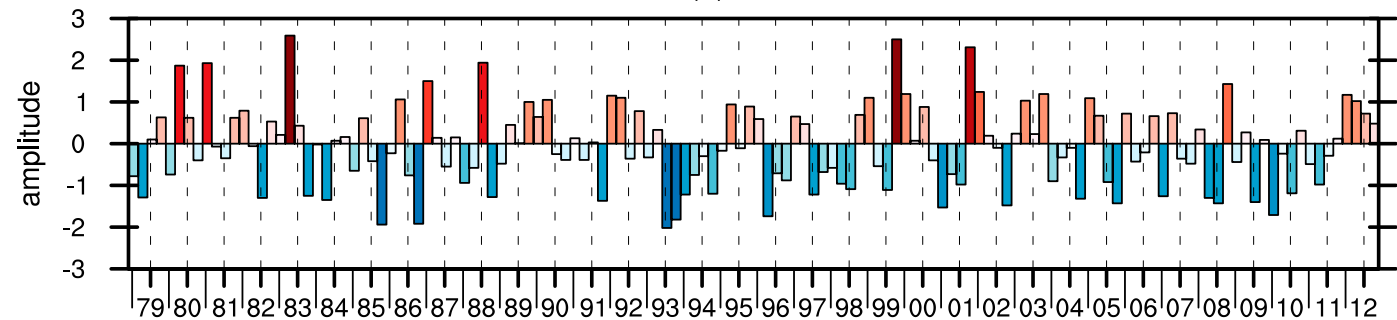

(d) $\overline{\mathrm{SPI}}$

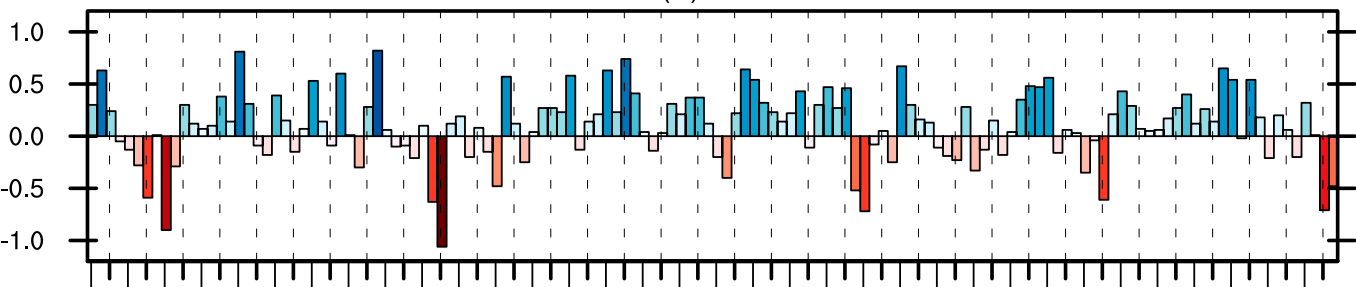

(e) $\overline{\text { PDSI }}$

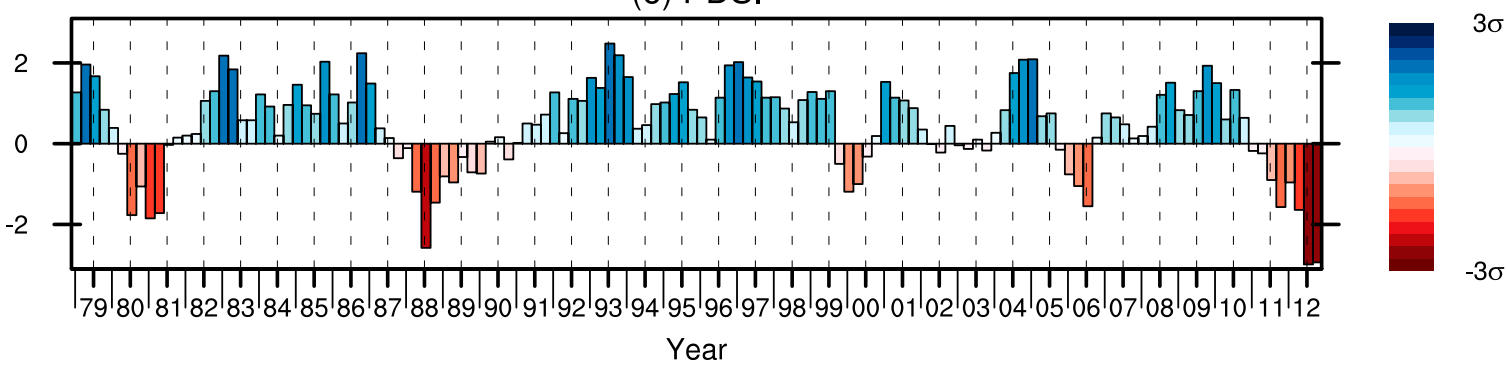

FIG. 5. As in Fig. 4, but for 1979-2012. 
TABLE 1. The top 10 driest and wettest boreal springs (MAM), based on the SPI and PDSI averaged over the entire Great Plains, northern Great Plains, and southern Great Plains. Springs during the 1930s are in bold. The springs are ranked from top (driest on record) to middle (10th driest), followed by middle (10th wettest) to bottom (wettest on record).

\begin{tabular}{|c|c|c|c|c|c|c|}
\hline & \multicolumn{2}{|c|}{ Great Plains } & \multicolumn{2}{|c|}{ Northern Great Plains } & \multicolumn{2}{|c|}{ Southern Great Plains } \\
\hline & SPI & PDSI & SPI & PDSI & SPI & PDSI \\
\hline \multirow[t]{2}{*}{ Driest } & 1925 & 1934 & 1934 & 1934 & 1936 & 1925 \\
\hline & 1934 & 1925 & 1958 & 1931 & 1925 & 1954 \\
\hline \multirow[t]{2}{*}{$\downarrow$} & 1936 & 1981 & 1980 & 2012 & 1972 & 1963 \\
\hline & 1956 & 1963 & 1926 & 1977 & 1954 & 1956 \\
\hline \multirow[t]{2}{*}{$\downarrow$} & 1988 & 1931 & 1988 & 1988 & 1963 & 1967 \\
\hline & 1972 & 2012 & 1956 & 1989 & 1967 & 1934 \\
\hline \multirow[t]{3}{*}{$\downarrow$} & 1963 & 1956 & 1925 & 1926 & 1986 & 1981 \\
\hline & 1967 & 1954 & 1928 & 1981 & 1971 & 2006 \\
\hline & 1954 & 1977 & 1931 & 1925 & 1956 & 2000 \\
\hline 10th driest & 1996 & 1988 & 1994 & 1990 & 1930 & 1936 \\
\hline \multirow[t]{2}{*}{ 10th wettest } & 1975 & 1995 & 1953 & 1996 & 1923 & 1922 \\
\hline & 1927 & 1942 & 1975 & 1975 & 1929 & 1993 \\
\hline \multirow{2}{*}{$\uparrow$} & 1929 & 1920 & 1922 & 1973 & 1997 & 1920 \\
\hline & 1938 & 1993 & 1995 & 1995 & 1979 & 1997 \\
\hline \multirow[t]{2}{*}{$\uparrow$} & 1990 & 1927 & 1998 & 1997 & 1945 & 1983 \\
\hline & 1945 & 1997 & 1979 & 2001 & 1957 & 1958 \\
\hline \multirow[t]{3}{*}{$\uparrow$} & 1944 & 1983 & 1927 & 1983 & 1944 & 1979 \\
\hline & 1979 & 1975 & 1938 & 1986 & 1990 & 1949 \\
\hline & 1922 & 1979 & 2007 & 1927 & 1922 & 1975 \\
\hline Wettest & 1973 & 1973 & 2011 & 1979 & 1973 & 1973 \\
\hline
\end{tabular}

Wilcoxon signed-rank test) for HWN and HWD, due to the lack of heat wave activity after wet springs. Hotter heat waves are more obvious in the northern Great Plains (Fig. 6c; Fig. S7c), where event anomalies are $\sim 2^{\circ} \mathrm{C}$ warmer than those in the southern Great Plains, despite their shorter durations and fewer recurrences. In terms of HWN, there are $\sim 0.6-0.8$ more events, on average, after a dry spring than after a wet spring, and these tend to be $\sim 1.4^{\circ}-1.8^{\circ} \mathrm{C}$ warmer and $\sim 2-3$ days longer (Figs. $7 \mathrm{a}-\mathrm{c}$ ). The significance in the difference between regionally averaged composites is tested by randomly resampling 1000 sets of 10 -yr composites, made up of any summer between 1920 and 2012; this tests whether each heat wave composite could happen by chance after anomalously wet, dry, or average spring preconditioning. The error bars of the resampled 1000 composites signify the 5th and 95th percentiles; thus, for the dry-spring composites, HWN, HWD (based on SPI only) and HWA are unlikely to have occurred by pure chance alone (i.e., are statistically significant). The significant differences in heat wave activity over the Great Plains between the wet and dry spring composites suggests that initial summertime surface conditions are an important factor in determining variations in summer heat wave activity.

\section{d. Dry springs and heat wave timing}

For the HWT composites (from SPI-ranked springs), all three heat wave classes (i.e., earliest, longest, hottest) emerge significantly earlier following a dry spring than a wet spring over the Great Plains and far eastern United States (Fig. 8). The earliest heat waves commence around mid-late June in the dry-spring composite on average, whereas the wet-spring composite events occur well into July/early August (Figs. 8a,b). It is worth noting that more stations are excluded from the wet-spring composite due to a lack of heat wave activity (less than $50 \%$ of years in each decade; see the methods section), particularly across the southern Great Plains. This may be due to seasonal atmospheric conditions that persist well beyond spring that dampen any heat wave development, or the anomalously wet surface conditions suppressing heat accumulation through evaporative cooling. Around $25 \%$ of stations across the United States show a statistically significant difference in the HWT of their earliest heat wave between the dry and wet composites at the $90 \%$ level (stations with a yellow outline in Fig. 8). A possible argument is that the earlier HWT is not necessarily indicative of warmer conditions, but arises from the greater frequency of events (e.g., summers where HWN > 2) after warm dry springs compared to cooler and wetter springs. This assumption is tested for summers where only one event emerges (i.e., $\mathrm{HWN}=1$; discarding multiple event summers). The results (not shown) indicate that even in the case of single event summers, heat waves occur earlier following dry springs compared to wet springs. Therefore the difference in HWT between the wet- and dry-spring composites is not necessarily due to event frequency; however, this may partially explain some disparity in warm summers where 
(a) HWN
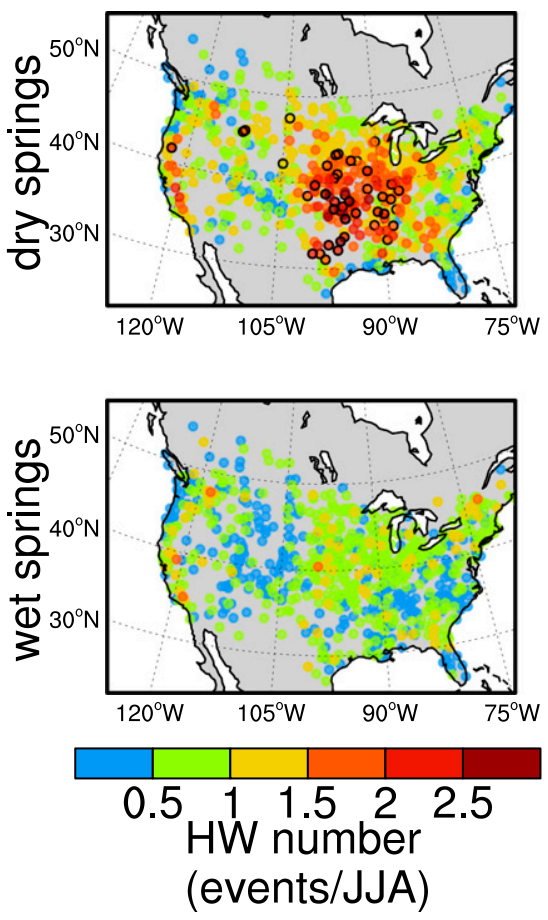

(b) HWD
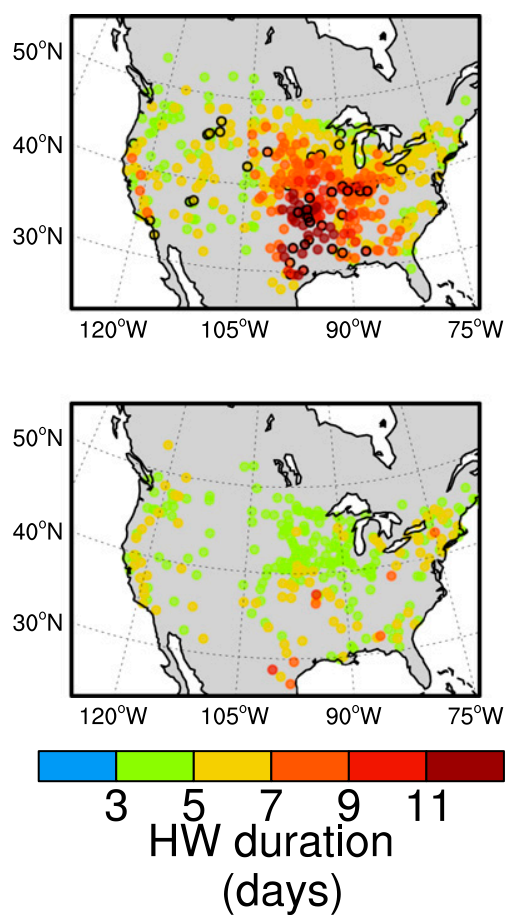

(c) HWA
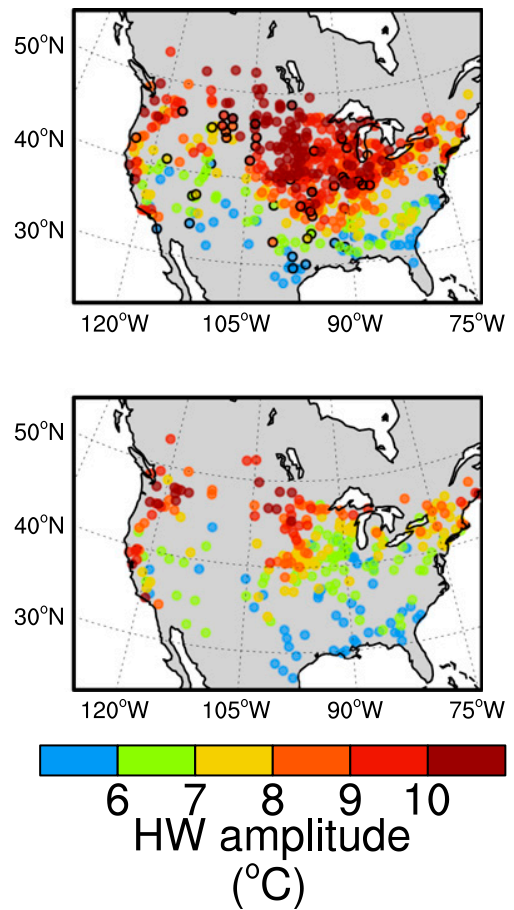

FIG. 6. Composite of summer heat wave metrics following the (top) 10 driest and (bottom) 10 wettest springs over 1920-2012, based on the SPI averaged across the Great Plains; (a) HWN, (b) HWD, and (c) HWA. The sparsity of points in the bottom panels for HWD and HWA reflects the lack of heat wave activity in more than $50 \%$ of the summers for the 10 -yr samples (as described in the methods section). Black outlined circles indicate stations that show a statistically significant difference at the $90 \%$ level between composites, based on a two-sample Wilcoxon signed-rank test (Hollander and Wolfe 1999). Significant differences are only marked on the dryspring composite maps.

HWN $>3$ events or when wet summers follow wet springs (i.e., persistence of atmospheric conditions).

The HWT values of the longest and hottest events are virtually identical for each of the composites (Figs. 8c-f), as protracted heat waves develop when conditions allow for heat accumulation in the lower troposphere, amplifying heat wave intensity (Miralles et al. 2014). Across the Great Plains, these events tend to emerge in late June/early July following dry springs, with events developing earlier (later) in the northern (southern) region (Fig. S7d). On average, the earliest heat waves in the dry-spring composite commence around 27 June, while the longest and hottest events develop $\sim 8-10$ days later (Fig. $7 d$, red dots). Events following wet springs tend to emerge between 17-19 days (earliest) and 16-17 days (longest, hottest) after the dry-spring events. Averaged over the Dust Bowl decade, the earliest heat waves emerged around 3-4 July, closer to the dry-spring composite as expected (not shown). As such, the drought severity in the 1930s may have partly contributed to earlier heat emergence, despite only three springs featuring in the top 10 driest (1931, 1934, 1936; see Table 1).
All three classes of HWT following dry springs are statistically significant (i.e., dry-spring HWTs lie below the 5th percentile of the resampled decades). Following a wet spring, the HWT of all heat wave classes lie toward the far end of the resampled distribution, however they are only statistically significant for the SPI-ranked springs. Averaged over the northern Great Plains, the dry-spring HWT lies farther toward the tail (i.e., occurs much earlier) of the resampled distribution, more so than the wet-spring HWT (i.e., occurs near the center of the resampled distribution; Fig. S7d), as for HWN and HWA. The evidence implies that dry northern soils help determine the emergence date of a heat wave, as well as their recurrence and severity. For the southern Great Plains, where the variance of precipitation is greater (Seager and Hoerling 2014), wetter springs appear to dampen heat wave activity (HWN, HWD, HWA) and delay emergence (HWT) more so than northern Great Plains heat waves that form following wet springs (Fig. S7, bottom panels). Another notable difference between the regions is that heat waves commence $\sim 10$ days earlier in the north compared to the south. 
(a) HWN

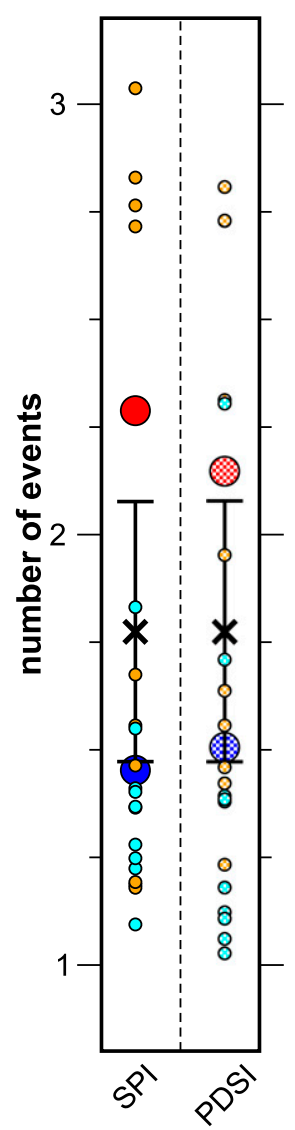

(b) HWD

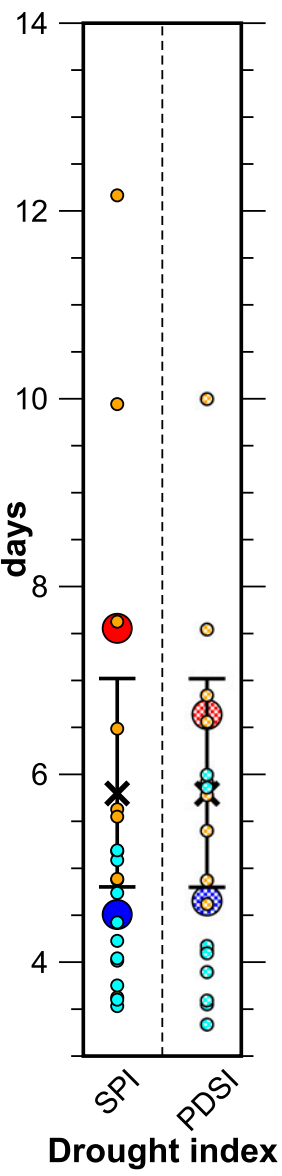

(c) HWA

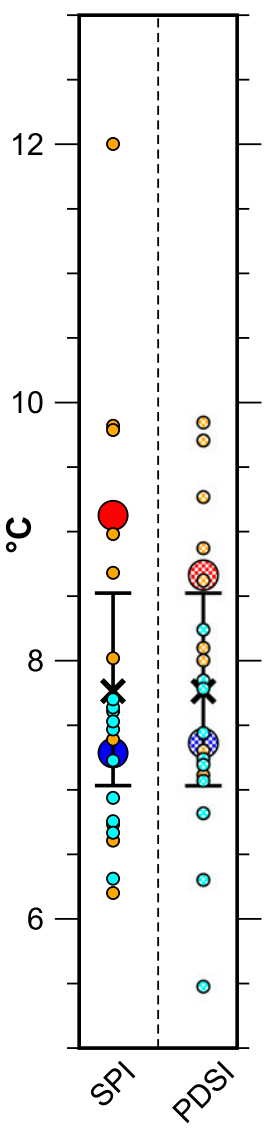

(d) HW timing

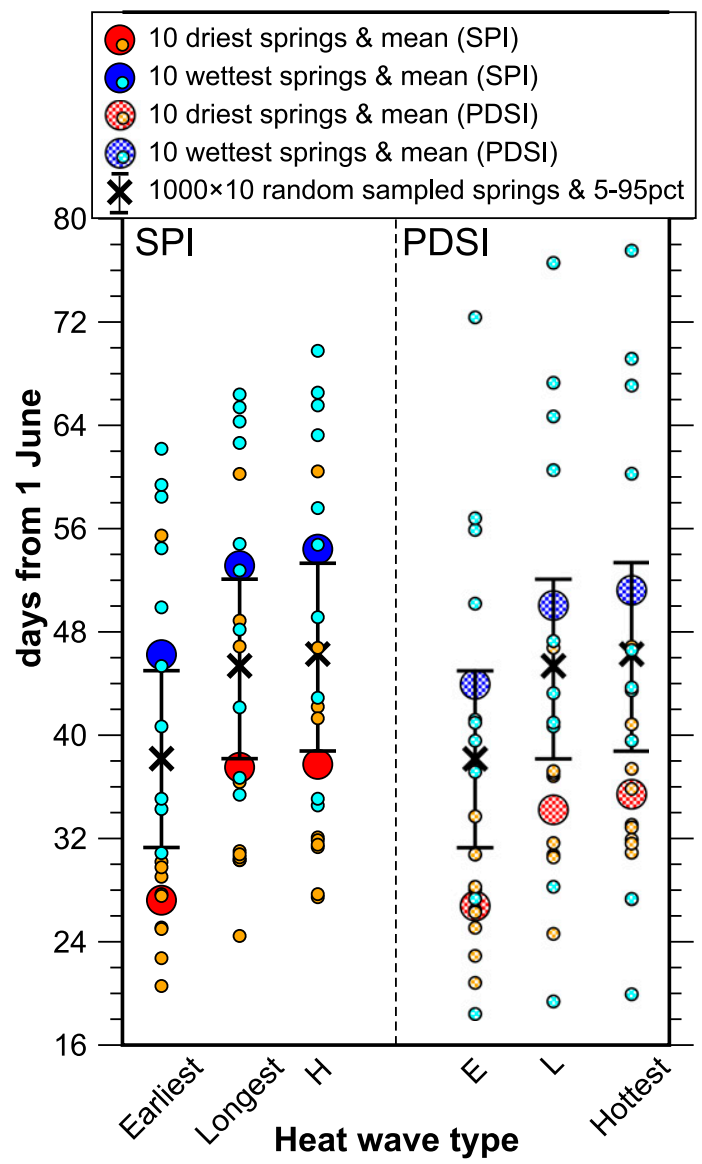

FIG. 7. Summer heat wave metrics from the 10 driest and 10 wettest springs over 1920-2012, averaged across the Great Plains: (a) HWN, (b) HWD, (c) HWA, and (d) heat wave timing (HWT). HWT is shown for the earliest, longest, and hottest heat waves. HWN encompasses all summer heat waves, while HWD and HWA are applicable to the longest and hottest heat waves, respectively. Small filled/shaded orange (light blue) circles represent individual summers following the 10 driest (wettest) springs based on the drought indices, while the large filled red and blue circles represent the summer composite averages. Solid (shaded) circles represent the metrics ranked using the SPI (PDSI). As a test of significance, 1000 sets of 10 randomly sampled years are averaged over all stations in the Great Plains (crosses), with the error bars showing the 5th and 95th percentiles. As such, the composite averages (large circles) lying outside the error bars are unlikely to have occurred by chance alone. The ranking of wet/dry springs for each region is taken from the years in Table 1.

\section{e. Biases in the $20 C R$}

Following on from quantifying the link between anomalous spring conditions and heat wave activity, we now investigate the typical circulation patterns associated with heat waves that occurred over the northern or southern Great Plains (or both); for this we utilize the 20CR gridded ensemble. ${ }^{6}$ Before analyzing the circulation we assess the suitability of the $20 \mathrm{CR}$ in capturing heat wave metrics for the three dry-spring summers from the

\footnotetext{
${ }^{6}$ Note that $20 \mathrm{CR}$ does not assimilate temperature observations but is constrained by surface pressure; see Compo et al. (2011) for details.
}

1930s (1931, 1934, and 1936; see Table 1). A comparison between the GHCN stations and the 20CR ensemble shows that the gridded product broadly captures the location of the HWD and HWN centers over the Great Plains, but it greatly overestimates the HWD by more than 15 days (Fig. 9a). The gridded ensemble also simulates a strong northwest bias, particularly evident in 1934, which is difficult to verify given the sparsity of available Canadian stations in the 1930s with long homogeneous records.

Given the biases in HWD, it follows that HWF biases exist in 20CR (Fig. S8a) as HWD and HWF are proportional, although HWA shows slightly better agreement with the stations over the Great Plains and into southern Canada (Fig. S8b). For other exceptional 


\section{Ranked by Great Plains SPI}
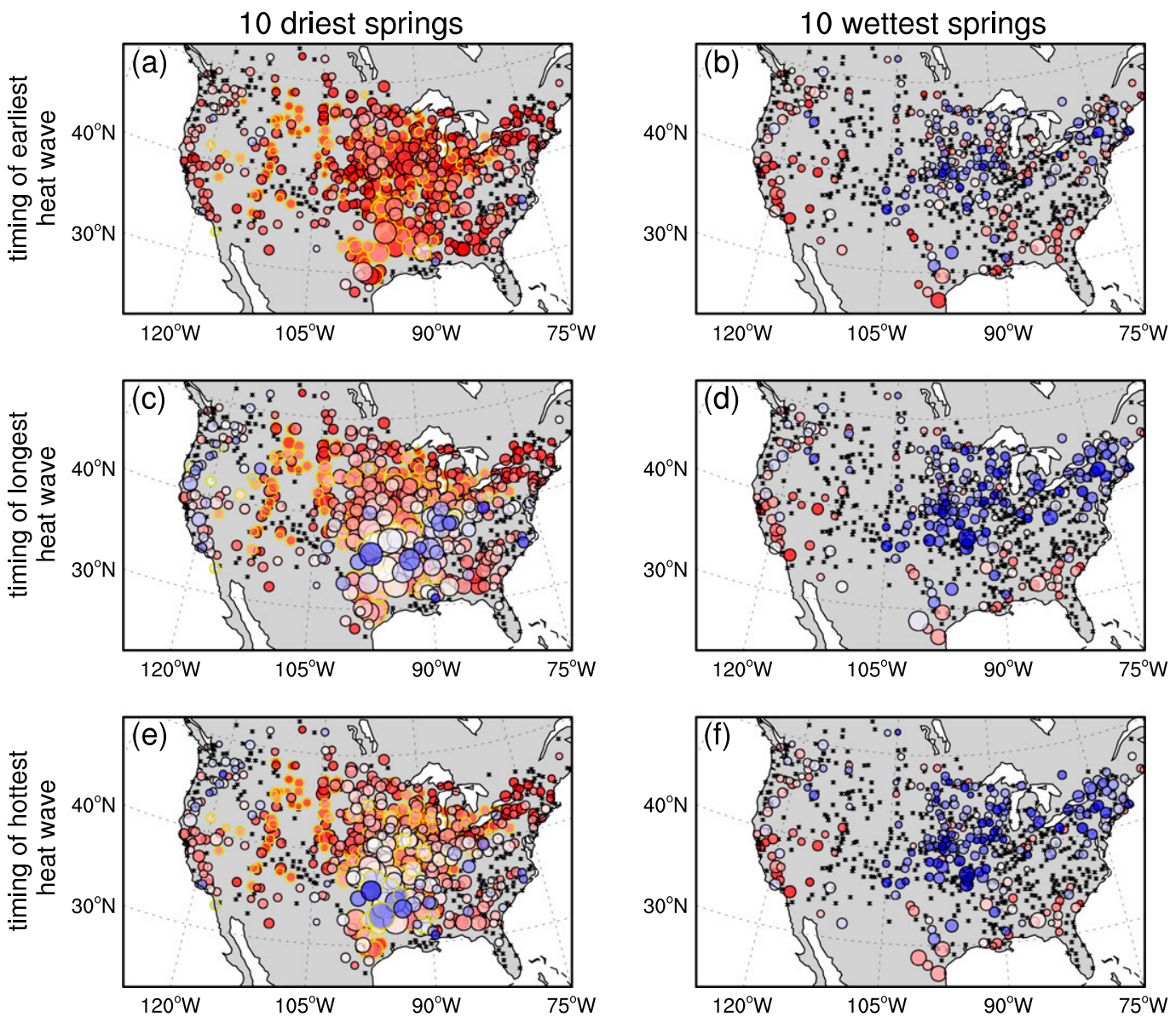

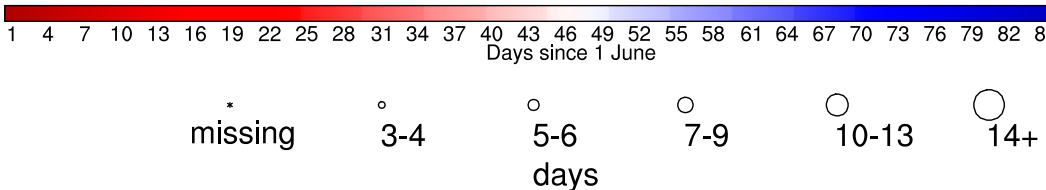

FIG. 8. Composite of summer heat wave timing (HWT; shaded) following the (left) 10 driest and (right) 10 wettest springs over 1920-2012, based on the SPI averaged across the Great Plains. (a),(b) HWT of the earliest event, (c),(d) HWT of the longest event, and (e),(f) HWT of the hottest event. HWT is measured as days since 1 June, where dark red (blue) indicates the start (end) of summer. The circle size indicates the average HWD (in days) of the summer heat waves for each composite for a particular station, while the black asterisks indicates stations that have less than $50 \%$ of summers for the 10 -yr samples. Yellow circles indicate stations that show a statistically significant difference at the $90 \%$ level between composites for the HWT only, based on a two-sample Wilcoxon signed-rank test. The proportion of stations across the United States and Canada that show statistically significant timings based on the SPI ranking is $\sim 25 \%$.

heat wave summers in the northern and southern Great Plains, such as 1954 and 1988, the biases in HWF are smaller in magnitude (not shown). The comparison between 20CR and GHCN stations is marginally better for HWN for the three prominent Dust Bowl summers (Fig. 9b) although specific regional biases are apparent over California and the southeast United
States. Taking these biases into account, we utilize 20CR for identifying the types of synoptic conditions experienced just prior, during, and in the follow-on week after the earliest heat waves. Recent work by Donat et al. (2016) highlighted the magnitude and spatial biases for temperature in 20CR over the Great Plains, and yet considered it applicable in investigating 
(a) HWD
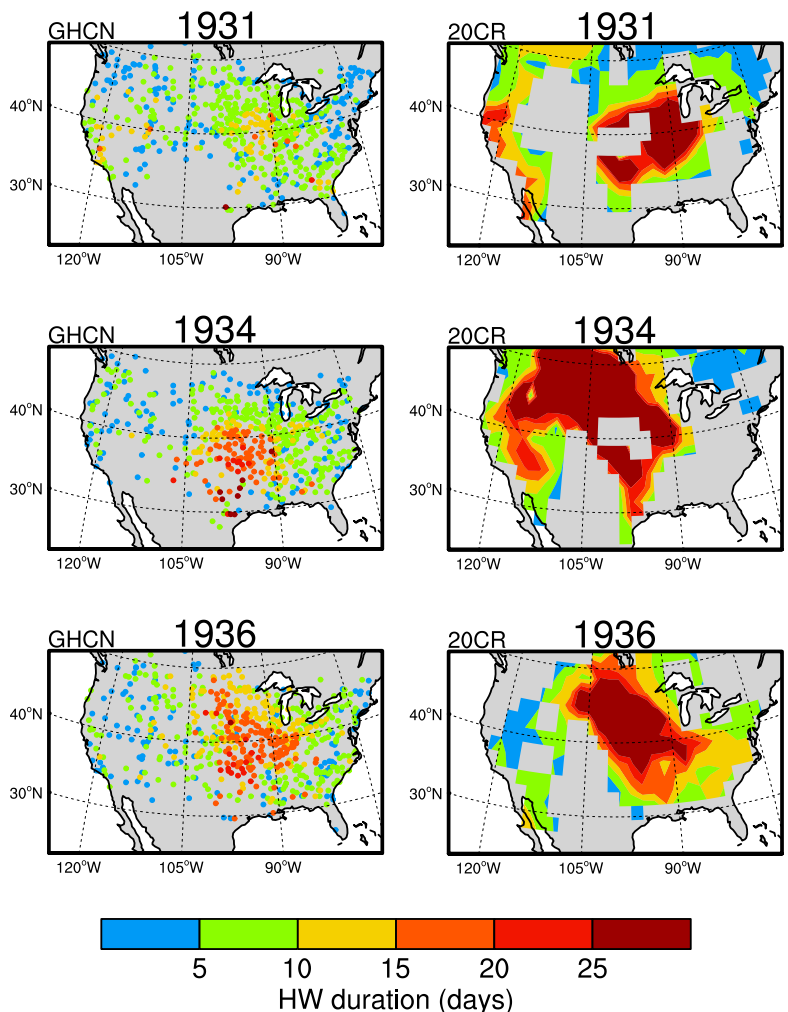

\section{(b) HWN}
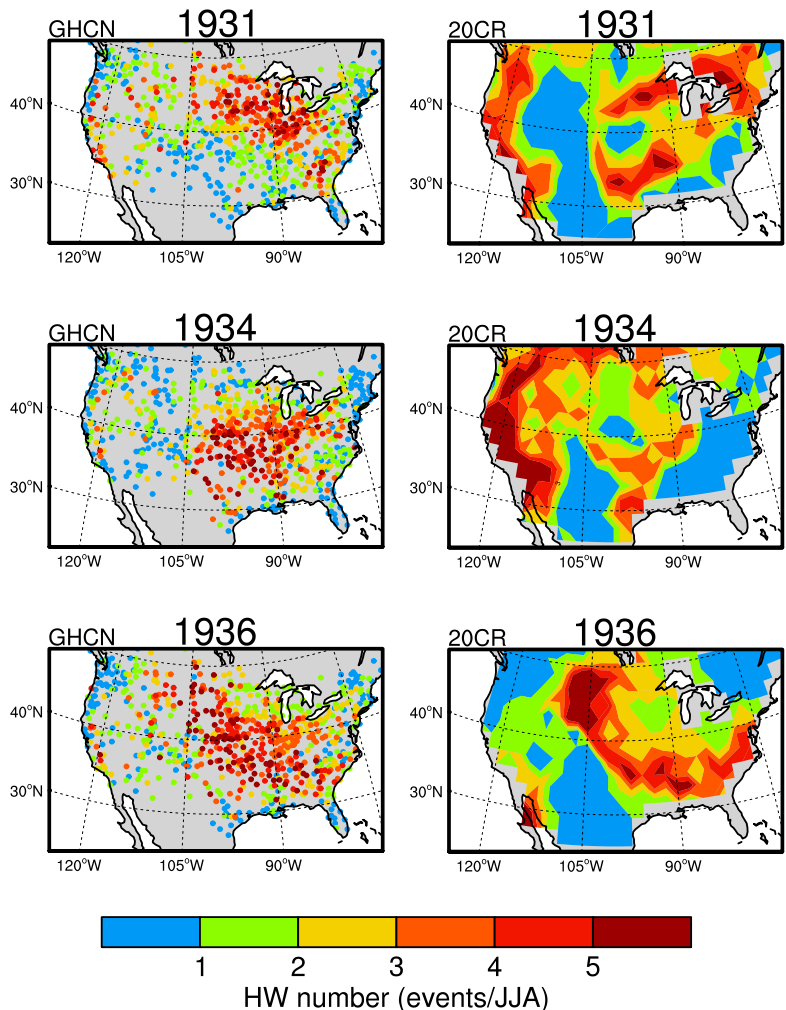

FIG. 9. Comparison of (a) HWD and (b) HWN between (left) GHCN-daily station observations and (right) 20CR for the summers of (top) 1931, (middle) 1934, and (bottom) 1936. The equivalent for HWF and HWA is shown in Fig. S8.

the continental-wide atmospheric circulation during extreme summers in isolation.

\section{f. Aggregating exceptional heat waves}

To reiterate, we only investigate the synoptic conditions of the earliest summer events. This conservative approach of evaluating the earliest heat waves instead of all heat waves prevents potential contamination from the same stationary synoptic pattern that could persist for multiple weeks throughout summer, spawning numerous heat waves. Events are aggregated based on timing only when heat wave summers are classified as exceptional in terms of HWF. This is determined by ranking the spatially averaged HWF values separately over the northern and southern Great Plains, for every summer from 1920 to 2012. HWF is chosen as it combines information from HWD and HWN. High HWF values are generally associated with summers that feature the longest and hottest heat waves; these have the greatest impact on communities and infrastructure in water-limited regions (e.g., Steffen et al. 2014). We define exceptional heat wave summers as those in the top third of all summers ranked separately for both the northern and southern Great Plains (i.e., 31 out of a possible 93 summers). Summers with exceptional HWF values in both the northern and southern Great Plains are then placed in a separate group that represents the entire Great Plains; these are determined to be the most severe heat waves covering a wider area. The ranked summers and the resultant HWF values averaged over each region are listed in Table 2 . The combined northern and southern Great Plains composite consists of 13 summers (and larger average HWF), while the northern and southern Great Plains composites feature 18 summers each (lower HWF). A sufficiently high percentage of stations $(>70 \%)$ display at least one heat wave event during these exceptional summers making the comparison between the regional composites fair (Fig. S9). Temporal aggregation of the circulation over the weeklong phases around the earliest heat wave start date ( $10 \%$ of stations; see methods section) is applied only for the exceptional heat wave summers for each region.

An example of the anomalous MSLP in week 1 (17 days) of the heat wave start date for the exceptional 
TABLE 2. Summers with exceptional heat wave activity, defined as the top third of HWF across the distribution over 1920-2012 $(N=31)$. The top third HWF values are taken from the northern and southern Great Plains separately $(N=18)$, whereas the HWF values in the Great Plains column indicate summers when both the regions exhibit exceptional heat wave activity $(N=13)$. The years are listed in descending order (i.e., highest to lowest) and those in bold (bold with an asterisk) are boreal summers following weak-moderate (strong) El Niño events, based on MSLP and SST-based El Niño-Southern Oscillation metrics. Years listed in italics (italics with an asterisk) are boreal summers following weak-moderate (strong) La Niña episodes. Note that $\overline{\mathbf{H W F}}$ represents the average for the composites for each region.

\begin{tabular}{|c|c|c|c|c|c|}
\hline \multicolumn{2}{|c|}{ Northern Great Plains } & \multicolumn{2}{|c|}{ Southern Great Plains } & \multicolumn{2}{|c|}{ Combined regions (North $\mid$ South) } \\
\hline Year & $\overline{\mathrm{HWF}}$ & Year & $\overline{\mathrm{HWF}}$ & Year & $\overline{\mathrm{HWF}_{N} \mid \mathrm{HWF}_{S}}$ \\
\hline 1988 & 15.04 & 1954 & 17.99 & 1936 & $19.59 \mid 19.97$ \\
\hline 1955 & 9.39 & 2011 & 17.57 & 1934 & $10.07 \mid 23.35$ \\
\hline 1941 & 8.42 & 1980 & 16.43 & 1953 & $\mathbf{7 . 0 2} \mid 13.83$ \\
\hline 1921 & 7.56 & 1952 & 16.22 & 1931 & $13.11 \mid 6.80$ \\
\hline 1995 & 7.29 & 1943 & 11.37 & 1930 & 7.35 | 11.65 \\
\hline 1976 & 6.76 & 1998* & 8.99* & 1933 & $10.03 \mid 8.75$ \\
\hline 1959 & 6.59 & 1925 & 8.75 & 1947 & $\mathbf{1 0 . 4 3} \mid 7.87$ \\
\hline 1940 & 6.49 & 2000 & 8.61 & 1937 & \begin{tabular}{l|l|} 
& \\
10.06 &
\end{tabular} \\
\hline 1991 & 5.91 & 2010 & 8.43 & $1983^{*}$ & $\mathbf{8 . 3 7} * \mid 7.82 *$ \\
\hline 1987 & 5.86 & 1951 & 7.63 & $2012 *$ & $6.15^{*} \mid 9.05^{*}$ \\
\hline 1948 & 5.84 & 1924 & 7.20 & 1935 & $4.78 \mid 6.50$ \\
\hline 1968 & 5.09 & 2007 & 7.10 & 1932 & $4.81 \mid 6.25$ \\
\hline 1949 & 5.07 & 2006 & 6.54 & 1956 & $4.57 \mid 6.33$ \\
\hline 1973 & 4.58 & 1978 & 6.21 & & \\
\hline 2002 & 4.25 & 1990 & 6.05 & & \\
\hline 2001 & 4.13 & 1969 & 5.97 & & \\
\hline 1964 & 4.13 & 1944 & 5.74 & & \\
\hline 1961 & 4.08 & 1922 & 5.72 & & \\
\hline$\overline{\mathbf{H W F}}$ & 6.47 & $\overline{\mathbf{H W F}}$ & 9.58 & $\overline{\mathbf{H W F}}$ & $\mathbf{8 . 9 5} \mid 10.43$ \\
\hline
\end{tabular}

summers from 1930 to 1937 is shown in Fig. 10. The cluster of stations varies every summer, ranging from tighter grouping in the northern United States in 1931 to a much wider and more scattered coverage in 1935 and 1936, including stations outside the Great Plains (in magenta). From 1933 to 1935 a strong positive MSLP anomaly is observed over the western United States coupled with a negative anomaly over the eastern regions. Weak positive MSLP anomalies over the Midwest are also a feature in 1930, 1931 and 1936. The positive MSLP anomalies over the Midwest show a tendency to strengthen during the week after the heat wave emerges (not shown). The positive MSLP anomaly represents an extension of the subtropical Pacific high, similar to the patterns present across the Midwest in the springs of 1934 and 1936, along with a weaker negative anomaly pattern over the eastern United States (Donat et al. 2016). The presence of a well-formed negative anomaly associated with southern United States heat waves leads to warm southerly anomalies from the Gulf of Mexico (Lau and Nath 2012).

\section{g. Circulation during exceptional heat waves}

We first assess how well 20CR captures the heat, in terms of $T_{\max }$ and $T_{\min }$ anomalies, in the weeks (week -1 , week 1 , week 2) encompassing the earliest heat wave
(Fig. 11), determined from the station heat wave dates. Circulation composites in the form of MSLP and 500-hPa geopotential height anomalies (Fig. 12) and horizontal temperature advection and 10-m winds (Fig. 13) provide an assessment of the weekly synoptic pattern evolution and flow of heat associated with regionally specific heat waves. Absolute MSLP patterns (rather than anomalies) that highlight the extension of the subtropical highs and weakening of the Midwest United States pressure trough are shown in Fig. S11. For temperature, despite the existence of regional biases between 20CR and GHCN observations (Fig. 11 for $T_{\max }$, Fig. S10 for $T_{\min }$ ), particularly along coastal and mountainous regions (i.e., Rocky Mountains at $\sim 110^{\circ} \mathrm{W}$ ), the broad-scale patterns of anomalous warming and cooling compare well. The disparity between $20 \mathrm{CR}$ and observations actually improves after the event emergence in weeks 1 and 2, most prominently in regions that experience the most severe heat (Figs. 11b,e,h and Figs. S10b,e,h).

For northern Great Plains exceptional heat waves, warm anomalies $>11^{\circ} \mathrm{C}$ appear in a small number $(\sim 15)$ of north-central stations $\left(\sim 50^{\circ} \mathrm{N}\right)$ in the week prior to the heat wave start (Fig. 11a). The heat progressively shifts southward and intensifies across the northeast $\left(T_{\max }>1.5^{\circ} \mathrm{C}\right)$ in week 1 , although temperatures moderate as the event fades in week 2 


\section{Earliest heatwave (days 1-7 after event start)}
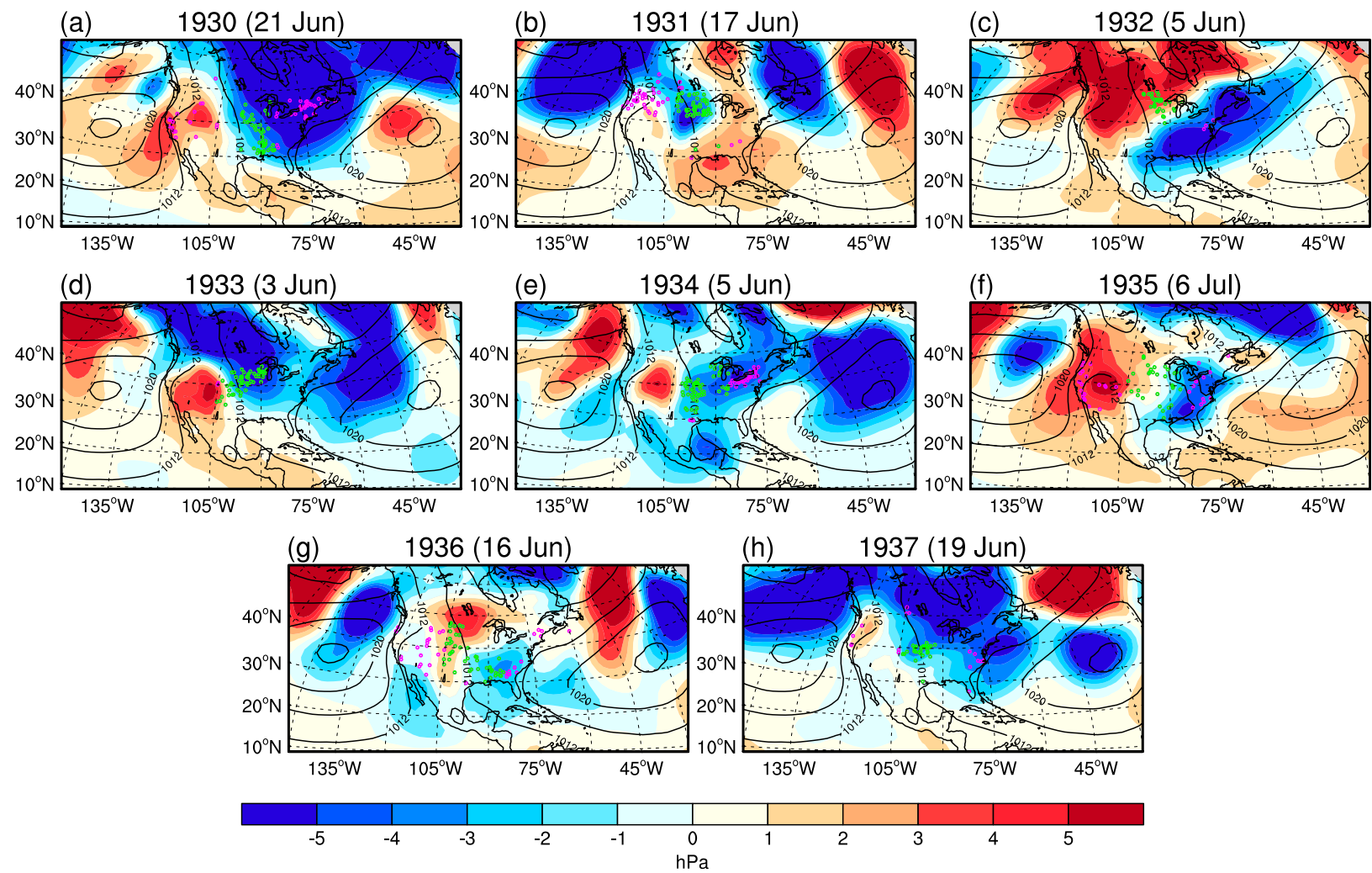

FIG. 10. Mean sea level pressure (MSLP) anomalies (color) and monthly climatologies (contours, from -2.5 to $2.5 \mathrm{hPa}$ with intervals of $1 \mathrm{hPa}$ ) averaged over select days (1-7 days) after the commencement of the earliest summer heat wave over 1930-37. The earliest summer heat wave is defined as the date when $10 \%$ of GHCN daily stations over each region, respectively, have registered a heat wave start (i.e., cumulative count of stations from 1 June). The locations of the $10 \%$ of stations that have registered a heat wave start are shown as green dots, while stations outside of the Great Plains that also exhibit a heat wave start are shown as magenta dots.

(Figs. 11b,c). The associative circulation pattern is one dominated by a prominent Rossby wave train propagating from the northeast Pacific in week 1, with an anomalous upper-level cyclonic pattern east of the Aleutian low region and a downstream anticyclone anomaly extending eastward encompassing the northern Great Plains (Fig. 12b). A strengthening surface trough over the west and a small westward extension of the Atlantic subtropical high are features during week 1 of the heat wave start (Fig. S11b). This results in anomalous easterlies over the southeast United States and southerlies extending north into the northern Great Plains (Fig. 13b). Despite a lack of temperature advection and a weakening of the anomalous upper-level anticyclone in week 2 after heat wave commencement (Fig. 12c), most of the northern Great Plains area remains warmer than average (Fig. 11c); however, the moderation in temperatures reflect the smaller $\mathrm{HWF}$ values over the northern Great Plains. The 500-hPa wave pattern is similar to that associated with heat waves over southeastern Canada, as simulated by a high-resolution atmospheric model forced with historical SST anomalies (Lau and Nath 2012), leading to strong subsidence and adiabatic warming. Thus, adiabatic heating from subsidence induced by an anomalous upper-level anticyclone, not surface temperature advection, appears to be more important in the emergence of northern Great Plains heat waves.

Heat originates in the Southeast prior to southern Great Plains heat waves, and then intensifies and extends northeastward, while $T_{\max }$ anomalies in the West and far Northwest remain anomalously cool $\left(<-1^{\circ} \mathrm{C}\right.$; Fig. 11d; $T_{\min }$ shown in Fig. S10d). An anomalous upperlevel trough extends to the surface over the central North America and farther west, while to the south an anomalous ridge spans the Gulf of Mexico to the northeastern United States (Fig. 12d). A Rossby wave train is apparent during week 1 of the heat wave, with an equivalent barotropic structure over the northern latitudes (Fig. 12e). As such, anomalous southerlies at the 


\section{Northern Great Plains}

\section{Southern Great Plains}
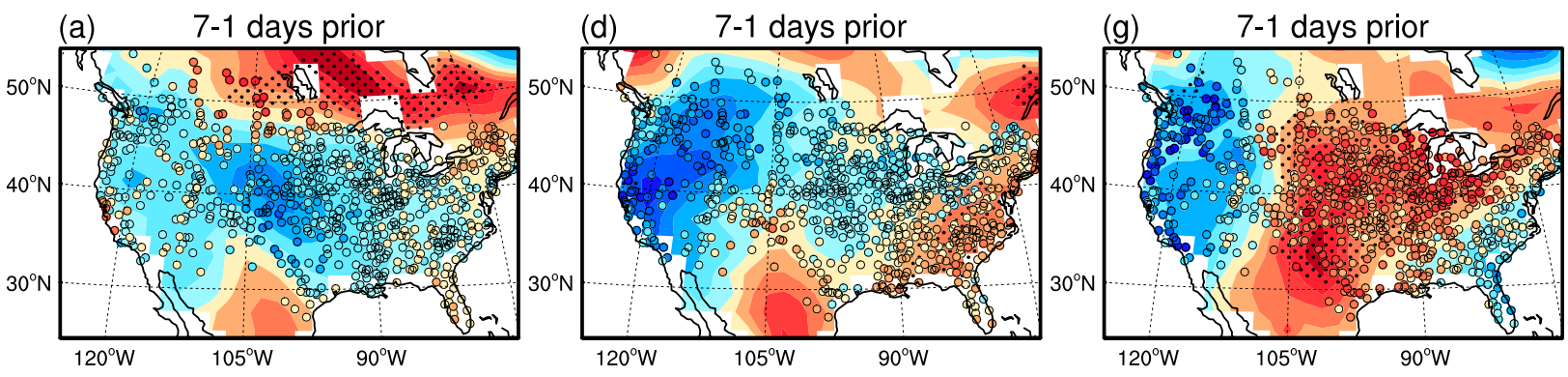

(b)

1-7 days after

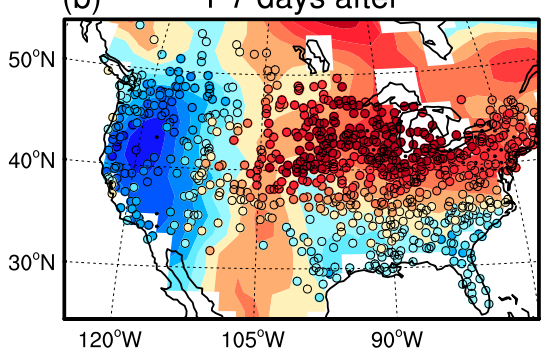

(e)

1-7 days after

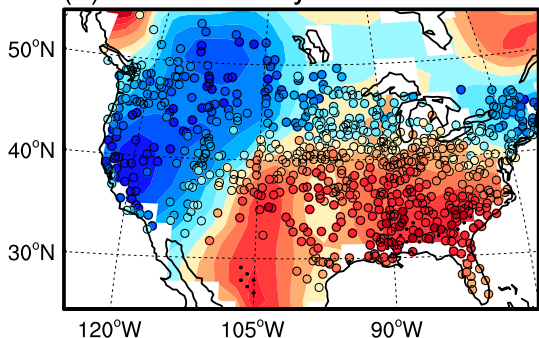

(h)

1-7 days after
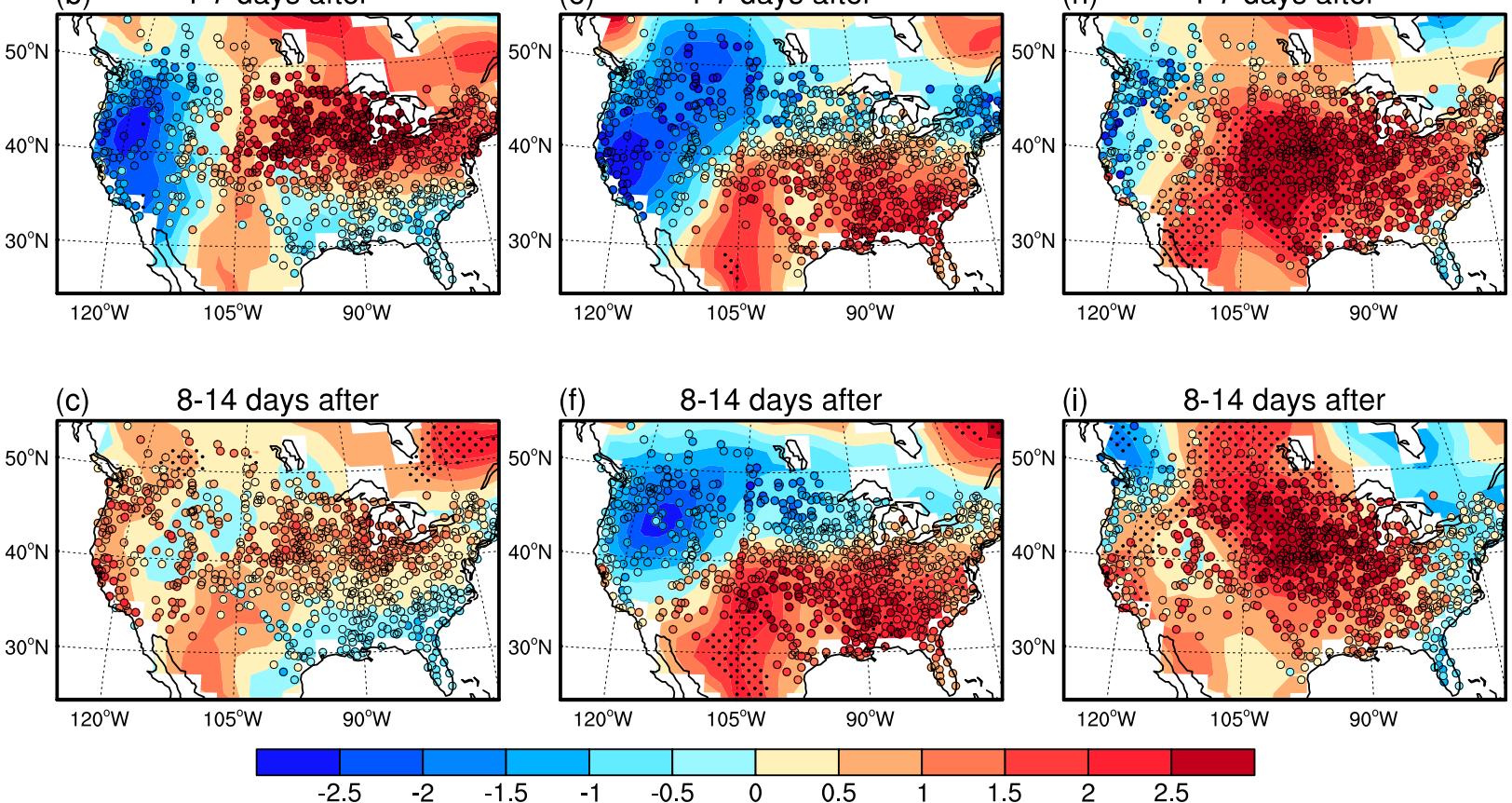

(f)

8-14 days after

(i)

8-14 days after

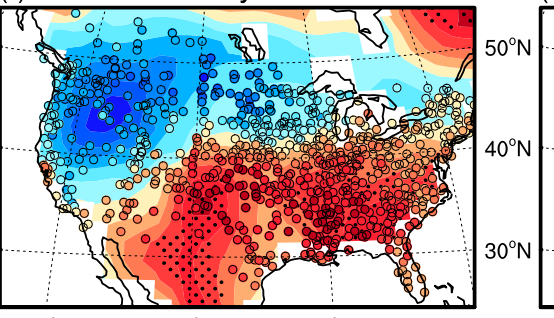

$120^{\circ} \mathrm{W} \quad 105^{\circ} \mathrm{W}$

$90^{\circ} \mathrm{W}$

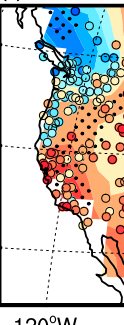

$120^{\circ} \mathrm{W}$
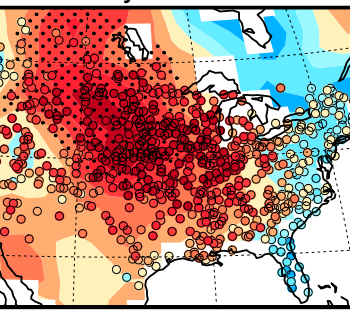

$0^{\circ} \mathrm{W}$

FIG. 11. Composite of $T_{\max }$ anomalies from 20CR (contours) and GHCN-daily stations (dots) averaged over select days (top) prior to (7-1 days prior), (middle) during (1-7 days after), and (bottom) after (8-14 days after) the earliest summer heat wave, for summers when there was exceptional heat wave activity over the (left) northern Great Plains, (middle) southern Great Plains, and (right) entire Great Plains. The earliest summer heat wave is defined as per Fig. 10. The years used in each composite, based on exceptional heat wave activity, are shown in Table 2. Significant $T_{\max }$ anomalies for 20CR are shown with stippling and represent anomalies that are considered significant at the $95 \%$ level based on a two-tailed test compared to 1000 randomly resampled composites.

surface advect relatively warm moist air from the Gulf of Mexico across the southern Great Plains (Figs. 13e,f). The small westward extension of the Atlantic subtropical high into the South is also apparent (Fig. S11e), weakening the Midwest trough. In week 2 after the heat wave start the upper-level ridge extending across southern United States appears slightly broader with the continued presence of the anomalous anticyclone over the southern Great Plains, with surface conditions continuing to force advection from the south. This allows $T_{\max }$ and $T_{\min }$ anomalies to remain anomalously warm (Fig. 11f and Fig. S10f), indicating the strength of subsidence and adiabatic warming associated with the anomalous anticyclone that dominates the anomalous advection.

Anomalous temperatures already exceeding $0.5^{\circ} \mathrm{C}$ are observed at numerous central stations prior to the Great Plains heat waves, with heat extending from the Deep South to the Great Lakes (Fig. 11g). The heat intensifies rapidly over the central and eastern regions as an upper-level anticyclonic anomaly and surface ridge anomaly strengthen (equivalent barotropic), sitting adjacent to a deepening surface trough to the east (Fig. 12h). Warm, dry air is advected toward the central Great Plains $\left(\sim 40^{\circ} \mathrm{N}\right)$, circulated from an already warm southern 


\section{Northern Great Plains}

\section{(a)}
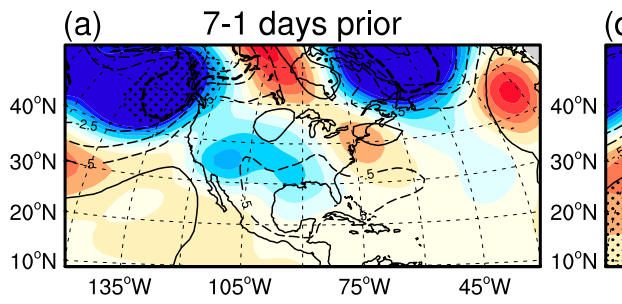

\section{Southern Great Plains}

(d)

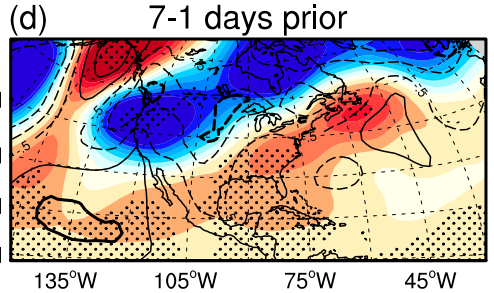

\section{Great Plains}

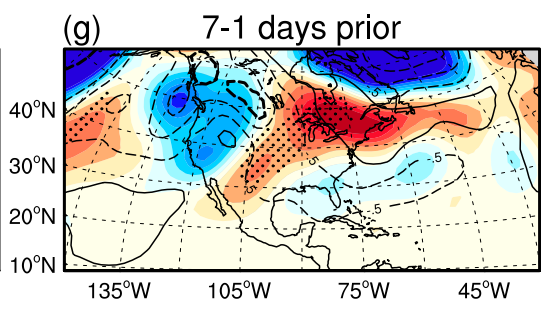

(b)

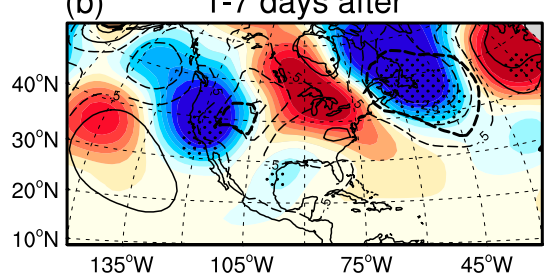

(e)

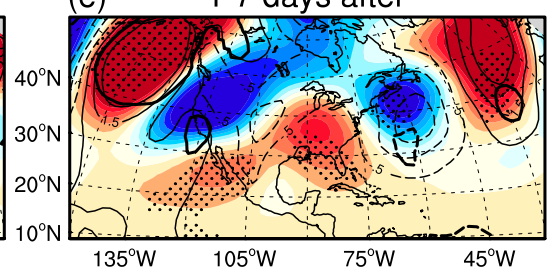

(h)

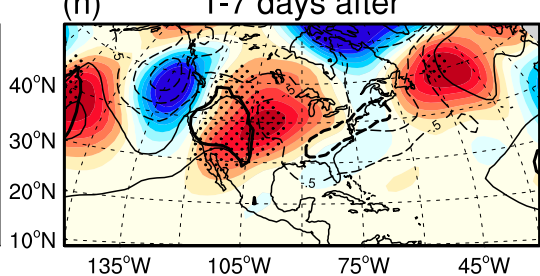

(c)

8-14 days after

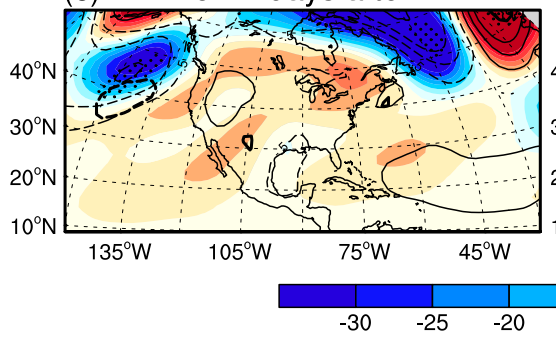

(f)

8-14 days after

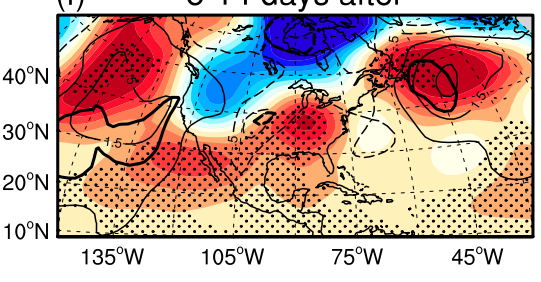

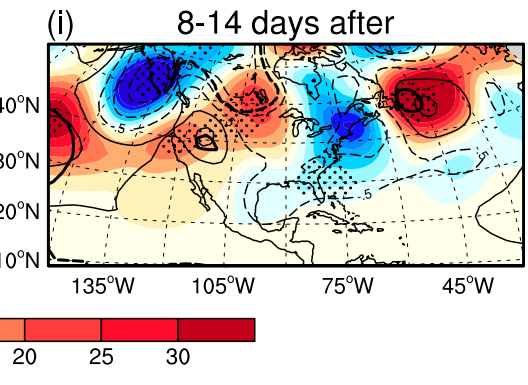

FIG. 12. Composite of 500-hPa geopotential height (color) and mean sea level pressure (MSLP; contours) anomalies averaged over select days (top) prior to (7-1 days before), (middle) during (1-7 days after), and (bottom) after ( $8-14$ days after) the earliest summer heat wave where there was exceptional heat wave activity over the (a) northern, (b) southern, and (c) entire Great Plains. The earliest summer heat wave is defined as in Fig. 10. Significant heights and MSLP are within the stippling and thick contours, respectively, and represent anomalies that are considered significant at the $95 \%$ level based on a two-tailed test compared to 1000 randomly resampled composites. MSLP contours cover -2.5 to $2.5 \mathrm{hPa}$ with intervals of $1 \mathrm{hPa}$.

United States and Mexico (Fig. 13h). As the heat wave develops, heat spreads rapidly westward across the Midwest, with temperature anomalies exceeding $2.5^{\circ} \mathrm{C}$, reducing the zonal temperature gradient to the west (Fig. 11i and Fig. S10i). The MSLP pattern in week 1 resembles the pressure dipole pattern associated with the dry springs of 1934 and 1936 (Donat et al. 2016) and early summer conditions from 1933 to 1936 (Fig. 10), and also represents the partial breakdown of the Midwest trough (Fig. S11i). The strong southward warm advection from the subsidence region in the Northwest leads to heat wave intensification and a protracted continental-wide heat wave. The anomalous circulation persists through week 2 (Fig. 12i), and despite a weakening of the anomalous surface ridge, warm advection persists in the South and Midwest (Fig. 13i). Choosing a later heat wave start date (e.g., greater station cumulative count threshold at 33\% instead of $10 \%$ ) results in similar synoptic patterns; for the Great Plains events, an anomalous surface ridge develops over the Midwest alongside a continental-wide upper level anticyclone anomaly that persists into the second week after the heat wave start (Fig. S12). This suggests that the circulation features are robust with respect to the heat wave start date selection.

\section{Discussion and conclusions}

This study quantified the record-breaking heat waves over the Great Plains in the 1930s Dust Bowl decade, assessing their spatial extent, duration, frequency, amplitude, and emergence timings. Recordbreaking heat wave events are diagnosed using in situ observations and the Twentieth Century Reanalysis, although the latter tends to show stronger and more extensive anomalies. Of the 13 summers that were classified as having exceptional heat waves (Table 2) 


\section{Northern Great Plains}

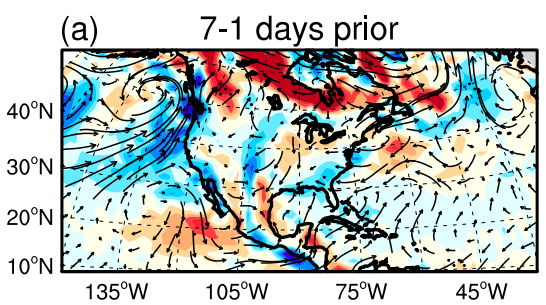

Southern Great Plains

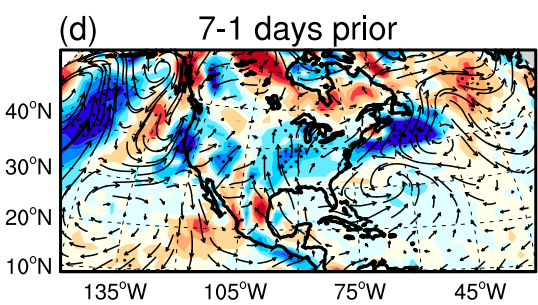

\section{Great Plains}

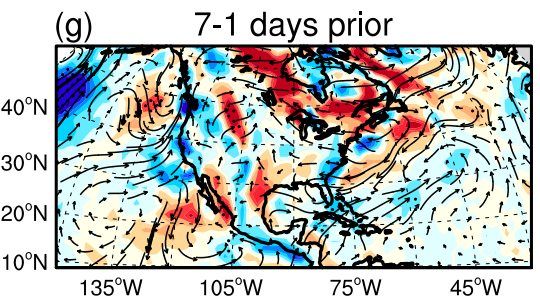

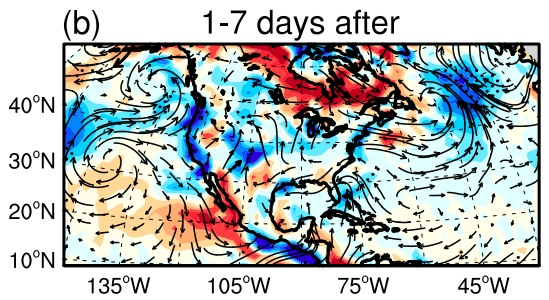
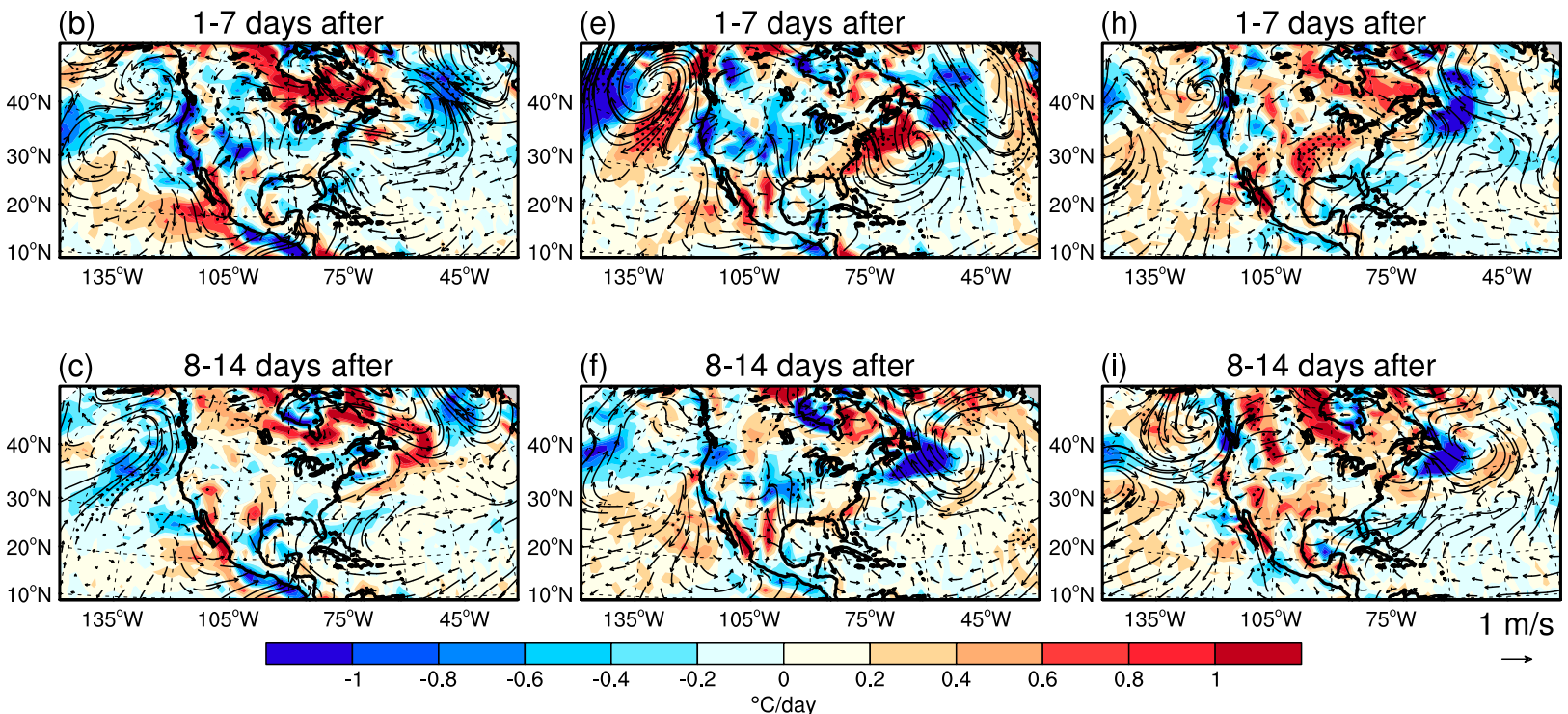

FIG. 13. Composite of anomalous horizontal temperature advection (color) and 10-m winds (vectors) averaged over select days (top) prior to (7-1 days before), (middle) during (1-7 days after), and (bottom) after (8-14 days after) the earliest summer heat wave where there was exceptional heat wave activity over the (left) northern, (middle) southern, and (right) entire Great Plains. The earliest summer heat wave is defined as in Fig. 10. Significant temperature advection anomalies are shown with stippling and significant wind anomalies are thicker; both represent anomalies that are considered significant at the $95 \%$ level based on a two-tailed test compared against 1000 sets of randomly resampled composites.

across the Great Plains, eight occurred in the 1930s. Important contributing factors to heat wave activity across the Great Plains, namely anomalously dry spring conditions and early-summer synoptic conditions, were then examined. It was shown that spring precipitation deficits alone (SPI) or a combination of decreased precipitation and anomalously hot conditions (PDSI) not only coincide with earlier summer heat wave emergence, but are also associated with significantly more frequent, longer, and hotter events, even in the case of summers where only one heat wave is observed. In general, dry springs over the northern Great Plains tend to result in earlier and hotter heat waves than for the southern Great Plains, despite longer and more frequent recurrence of events in the south. The risk of heat waves emerging early and redeveloping later in summer increases after a dry spring for the following reasons:
1) The surface is anomalously dry (e.g., early 1930s), such that evaporative cooling is essentially negligible, leading to heating of the lower boundary layer through increased sensible heat fluxes during the heat wave, amplifying the heat (Miralles et al. 2014; Yin et al. 2014).

2) The tendency exists for quasi-stationary upperlevel ridging and blocking, coinciding with a nearsurface anticyclone to persist from late spring to summer, that suppresses convection and disrupts advection of relatively moist air from the Gulf of Mexico (prolonging the dry conditions) as observed in $1934^{7}$ and 1936 (Cook et al. 2014; Donat et al. 2016).

\footnotetext{
${ }^{7}$ A similar upper-level blocking pattern occurred in the winter of 1934 as shown in Cook et al. (2014).
} 
1930-39

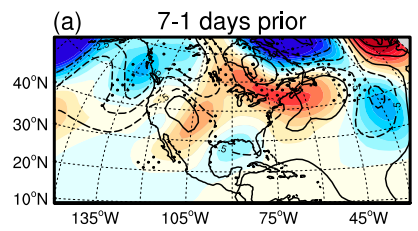

1950-59

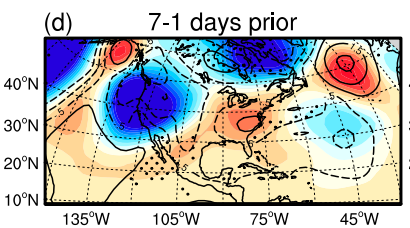

1980-89

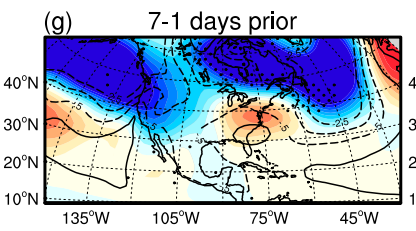

2003-12

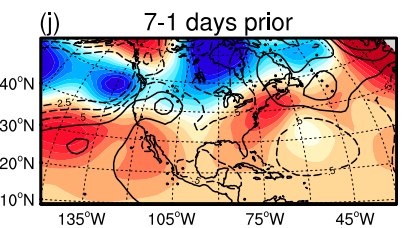

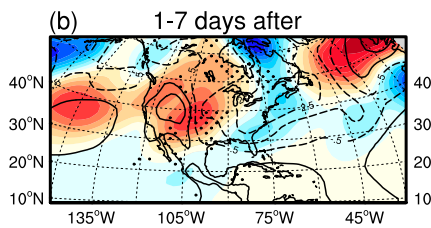
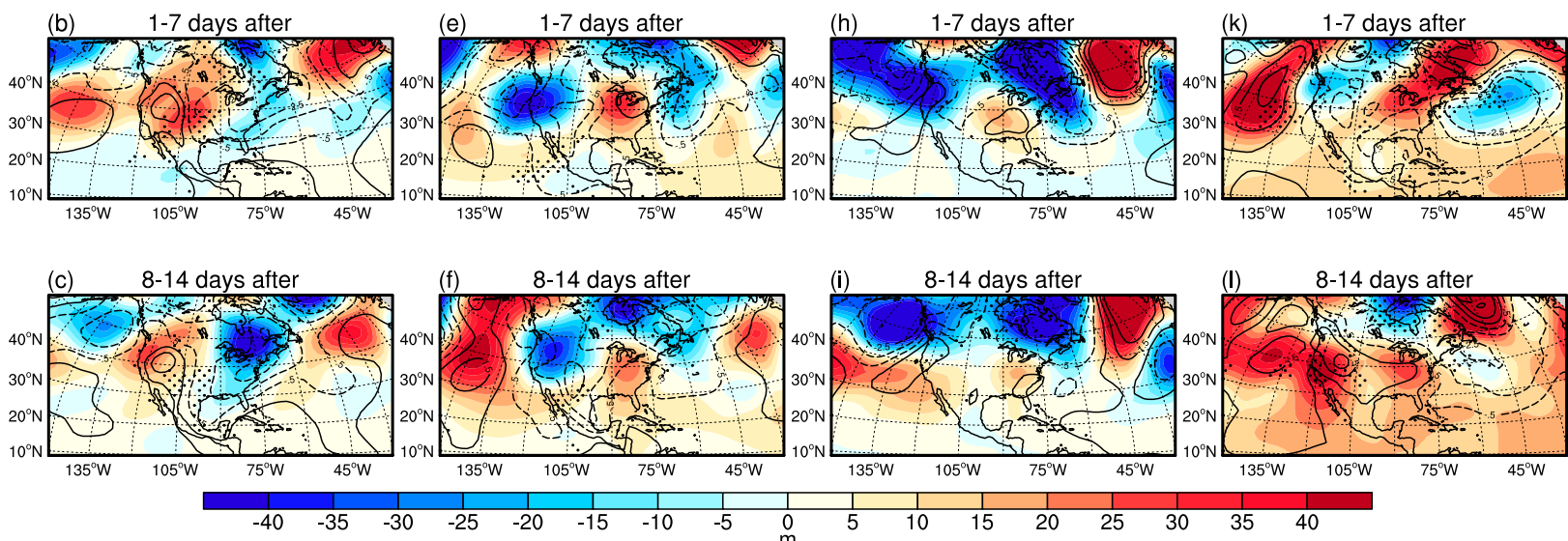

FIG. 14. Composite of 500-hPa geopotential height (color), mean sea level pressure (MSLP; contours) and horizontal temperature advection (stippling) anomalies averaged over select days (top) prior to (7-1 days before), (middle) during (1-7 days after), and (bottom) after (8-14 days after) the earliest summer heat wave when there was exceptional heat wave activity over the Great Plains, for (a)-(c) 1930-39, (d)-(f) 1950-59, (g)-(i) 1980-89, and (j)-(1) 2003-12. Only horizontal temperature advection anomalies $\geq 0.6^{\circ} \mathrm{C}$ day $^{-1}$ are shown, while MSLP contours cover -2.5 to $2.5 \mathrm{hPa}$ with intervals of $1 \mathrm{hPa}$. The earliest summer heat wave is defined as in Fig. 10.

To quantify the extent to which anomalously dry soil contributed to maintaining an upper-level ridge during the Dust Bowl heat waves would require running sensitivity experiments utilizing a coupled atmosphere-land surface model, including the role of SSTs (Cook et al. 2009). Such models have already been used to determine of the role of precipitation and temperature anomalies on soil moisture variations during drought over the Great Plains (Livneh and Hoerling 2016), and whether initial soil moisture conditions increase summer drought severity through feedbacks on precipitation (Saini et al. 2016). As for heat waves in general, sensitivity experiments based on the 2003 European heat waves have shown that a $25 \%$ reduction in soil moisture forces a positive height response in the midtroposphere sitting aloft a surface low (Fischer et al. 2007b). Similarly, Oglesby and Erickson (1989) also related soil moisture deficits to low surface pressures and upper-level ridging in the North American summer using a global atmospheric general circulation model. A possible next step would be to utilize a large enough ensemble of model experiments to test heat wave sensitivity to anomalous soil moisture perturbations and the impact on the overlying circulation (e.g., Fischer et al. 2007a,b).
A further question is why the heat waves in later decades were not as severe as those during the Dust Bowl. Figure 14 displays a comparison of the surface and upper-level circulation between the 1930s and the anomalously dry decades of the 1950s, 1980s, and late 2000s (2003-12), calculated for the weeks before, during, and after heat wave onset. The characteristic anomalous synoptic pattern with a blocking surface anticyclone and upper-level ridge that developed over the Midwest and northeast United States is apparent in the 1930s, along with the advection of anomalously warm air from the northwest to the Great Plains (Figs. 14a-c). Strong adiabatic warming induced by subsidence, along with warm advection, is typical of Midwestern heat waves (Lau and Nath 2012; Grotjahn et al. 2016, and references therein). In contrast, for the heat waves of the 1950s and 1980s we see an upper-level quasi-stationary anticyclone anomaly coupled to a weak surface high anomaly over the eastern United States (Fig. 14, middle columns); this synoptic pattern is conducive to warm moist air from the Gulf of Mexico. The composite circulation pattern over the 2003-12 decade shows a broad upper-level ridge anomaly stretching from the west Pacific to northeast United States and 
anomalous surface anticyclone over the west advecting warm air from the northwest in week 2 (Fig. 141). As such, temperature advection from the north was comparatively weaker, given the lack of an anomalously deep surface low over the southeast (i.e., weaker pressure gradient). This implies that the 1930s heat waves were more severe due to anomalous circulation patterns arising over the continent, leading to strong subsidence-induced warming during heat wave onset, followed by warm advection from the north increasing the event severity.

The link of heat wave to SSTs, both interannual and decadal, has not been covered in this study, although the role of SSTs in forcing historical North American heat waves is an active research area (e.g., Wang et al. 2014; Donat et al. 2016; McKinnon et al. 2016, and references therein). The broad consensus is that SSTs in the Pacific and Atlantic Oceans both acted as potential triggers and amplifiers to the Dust Bowl drought and heat waves (Donat et al. 2016), with idealized SST experiments supporting this argument (e.g., Schubert et al. 2004a,b), although dust forcing and land degradation may have extended the spatial extent of the drought (Cook et al. 2009, 2013). Anomalously warm Atlantic SSTs in the summer months effectively weakened the Great Plains low-level jet, amplifying drought triggered in the spring by Pacific SSTs (Brönnimann et al. 2009). However, for individual summers, such as 1934 and 1936, SST forcing from the tropical Pacific is thought to have played a minor role, as opposed to the bigger role played by the cool Pacific/ warm Atlantic in the 1950s drought (Cook et al. 2011). In general, La Niña events tend to increase the frequency of heat wave events across the United States (Jia et al. 2016), although this depends on how heat waves and summer seasons are defined, and the fact that the link is not very strong statistically (Kenyon and Hegerl 2008). Our exceptional heat wave summers occur more often following an El Niño (15 events) than a La Niña (10 events; see Table 2); however, La Niña episodes were associated with sporadic dry seasons in $1988 / 89$, 1999/2000, and 2010-12 (Figs. 5d,e).

Instead of tropical SSTs, it has been suggested that anomalously warm SSTs along the west coast of North America may contribute to drier than average springs, as indicated by a correlation patterns between central United States precipitation and northeast Pacific SSTs (Donat et al. 2016). The SST pattern of the 1930s warm spring and summers is somewhat opposite to that suggested to play a role in eastern United States heat waves in recent decades (i.e., cold North Pacific anomalies; McKinnon et al. 2016). It appears that protracted dry conditions over multiple seasons prior to the severest Dust Bowl summers, along with characteristic synoptic patterns that initially warmed the Great Plains through subsidence and then through advection, culminated in the record-breaking heat waves of the 1930s. In the decades since, vast improvements in land practices through irrigation and greater drought awareness (Cook et al. 2013) have likely reduced both the severity of drought-induced soil erosion and the risk of springtime dust storms, thus alleviating the threat of the Great Plains temperatures surpassing the Dust Bowl records. It is likely that warmer heat waves will arise in the future over central North America due to enhanced land-atmosphere feedbacks, given large-scale warming. Recent modeling evidence also suggests that the aforementioned heat wave synoptic patterns (i.e., characteristic of the Dust Bowl circulation with an upstream anticyclone over the North Pacific and blocking anticyclone over the central regions) is unlikely to change in the future (Teng et al. 2016). Critically, future work will be aimed at better understanding the role of SSTs in triggering Dust Bowl-type heat waves, the importance of spring precipitation deficits carrying through to summer, and whether an early-twentieth-century greenhouse gas forcing played any role in the Dust Bowl heat severity. The ultimate aim is to provide better predictive capability of the most severe heat waves across the Great Plains based on a set of key indicators.

Acknowledgments. This study forms part of the Transition into the Anthropocene (TITAN) project, funded by a European Research Council (ERC) Advanced Grant (EC-320691), and was further supported by the EUCLEIA project funded by the European Union's Seventh Framework Programme (FP7/2007-13) under Grant Agreement 607085. G. Hegerl is also supported by National Centre for Atmospheric Science (NCAS) and the Wolfson Foundation and the Royal Society as a Royal Society Wolfson Research Merit Award (WM130060) holder. We thank the National Oceanic and Atmospheric Administration/ National Climatic Data Center (NOAA/NCDC) for the use of the GHCN daily data. Support for the 20CR Project version $2 \mathrm{c}$ dataset is provided by the United States Department of Energy, Office of Science Biological and Environmental Research, and by the National Oceanic and Atmospheric Administration Climate Program Office.

\section{REFERENCES}

Abatzoglou, J. T., and R. Barbero, 2014: Observed and projected changes in absolute temperature records across the contiguous United States. Geophys. Res. Lett., 41, 6501-6508, doi:10.1002/ 2014 GL061441. 
Brönnimann, S., and Coauthors, 2009: Exceptional atmospheric circulation during the "Dust Bowl." Geophys. Res. Lett., 36, L08802, doi:10.1029/2009GL037612.

Compo, G. P., and Coauthors, 2011: The Twentieth Century Reanalysis Project. Quart. J. Roy. Meteor. Soc., 137, 1-28, doi:10.1002/qj.776.

Cook, B. I., R. L. Miller, and R. Seager, 2009: Amplification of the North American "Dust Bowl" drought through humaninduced land degradation. Proc. Natl. Acad. Sci. USA, 106, 4997-5001, doi:10.1073/pnas.0810200106.

_, R. Seager, and R. L. Miller, 2011: Atmospheric circulation anomalies during two persistent North American droughts: 1932-1939 and 1948-1957. Climate Dyn., 36, 2339-2355, doi:10.1007/s00382-010-0807-1.

,,-- , and J. A. Mason, 2013: Intensification of North American megadroughts through surface and dust aerosol forcing. J. Climate, 26, 4414-4430, doi:10.1175/ JCLI-D-12-00022.1.

$\longrightarrow,-$, and J. E. Smerdon, 2014: The worst North American drought year of the last millennium: 1934. Geophys. Res. Lett., 41, 7298-7305, doi:10.1002/2014GL061661.

Cowan, T., A. Purich, S. Perkins, A. Pezza, G. Boschat, and K. Sadler, 2014: More frequent, longer, and hotter heat waves for Australia in the twenty-first century. J. Climate, 27, 58515871, doi:10.1175/JCLI-D-14-00092.1.

Dai, A., 2011: Characteristics and trends in various forms of the Palmer Drought Severity Index during 1900-2008. J. Geophys. Res., 116, D12115, doi:10.1029/2010JD015541.

— , K. E. Trenberth, and T. Qian, 2004: A global dataset of Palmer Drought Severity Index for 1870-2002: Relationship with soil moisture and effects of surface warming. J. Hydrometeor., 5, 1117-1130, doi:10.1175/JHM-386.1.

Diffenbaugh, N. S., and M. Ashfaq, 2010: Intensification of hot extremes in the United States. Geophys. Res. Lett., 37, L15701, doi:10.1029/2010GL043888.

Donat, M. G., L. V. Alexander, H. Yang, I. Durre, R. Vose, and J. Caesar, 2013a: Global land-based datasets for monitoring climatic extremes. Bull. Amer. Meteor. Soc., 94, 997-1006, doi:10.1175/BAMS-D-12-00109.1.

_ precipitation extreme indices since the beginning of the twentieth century: The HadEX2 dataset. J. Geophys. Res. Atmos., 118, 2098-2118, doi:10.1002/jgrd.50150.

— A. A. King, J. T. Overpeck, L. V. Alexander, I. Durre, and D. J. Karoly, 2016: Extraordinary heat during the 1930s US Dust Bowl and associated large-scale conditions. Climate Dyn., 46, 413-426, doi:10.1007/s00382-015-2590-5.

Ferguson, C. R., and G. Villarini, 2012: Detecting inhomogeneities in the Twentieth Century Reanalysis over the central United States. J. Geophys. Res., 117, D05123, doi:10.1029/ 2011JD016988.

Fischer, E. M., S. I. Seneviratne, D. Lüthi, and C. Schär, 2007a: Contribution of land-atmosphere coupling to recent European summer heat waves. Geophys. Res. Lett., 34, L06707, doi:10.1029/2006GL029068.

— — - P. P. Vidale, D. Lüthi, and C. Schär, 2007b: Soil moisture-atmosphere interactions during the 2003 European summer heat wave. J. Climate, 20, 5081-5099, doi:10.1175/ JCLI4288.1.

Grotjahn, R., and Coauthors, 2016: North American extreme temperature events and related large-scale meteorological patterns: A review of statistical methods, dynamics, modeling, and trends. Climate Dyn., 46, 1151-1184, doi:10.1007/s00382-015-2638-6.
Hoerling, M., and A. Kumar, 2003: The perfect ocean for drought. Science, 299, 691-694, doi:10.1126/science.1079053.

Hollander, M., and D. A. Wolfe, 1999: Nonparametric Statistical Methods. John Wiley and Sons, 787 pp.

Jeong, D. I., L. Sushama, G. T. Diro, M. N. Khaliq, H. Beltrami, and D. Caya, 2016: Projected changes to high temperature events for Canada based on a regional climate model ensemble. Climate Dyn., 46, 3163- 3180, doi:10.1007/s00382-015-2759-y.

Jia, L., and Coauthors, 2016: The roles of radiative forcing, sea surface temperatures, and atmospheric and land initial conditions in U.S. summer warming episodes. J. Climate, 29, 41214135, doi:10.1175/JCLI-D-15-0471.1.

Jones, B., B. C. O'Neill, L. McDaniel, S. McGinnis, L. O. Mearns, and C. Tebaldi, 2015: Future population exposure to US heat extremes. Nat. Climate Change, 5, 652-655, doi:10.1038/nclimate2631.

Kenyon, J., and G. C. Hegerl, 2008: Influence of modes of climate variability on global temperature extremes. J. Climate, $\mathbf{2 1}$, 3872-3889, doi:10.1175/2008JCLI2125.1.

Koster, R. D., and Coauthors, 2004: Regions of strong coupling between soil moisture and precipitation. Science, 305, 11381140, doi:10.1126/science.1100217.

Lau, N.-C., and M. J. Nath, 2012: A model study of heat waves over North America: Meteorological aspects and projections for the twenty-first century. J. Climate, 25, 4761-4764, doi:10.1175/ JCLI-D-11-00575.1.

Livezey, R. E., and R. Tinker, 1996: Some meteorological, climatological, and microclimatological considerations of the severe U.S. heat wave of mid-July 1995. Bull. Amer. Meteor. Soc., 77, 2043-2054, doi:10.1175/1520-0477(1996)077<2043: $\mathrm{SMCAMC}>2.0 . \mathrm{CO} ; 2$.

Livneh, B., and M. P. Hoerling, 2016: The physics of drought in the U.S. central Great Plains. J. Climate, 29, 6783-6804, doi:10.1175/JCLI-D-15-0697.1.

Mattice, W. A., 1935: Dust storms. Mon. Wea. Rev., 63, 113-115, doi:10.1175/1520-0493(1935)63<113b:DS > 2.0.CO;2.

McKee, T. B., N. J. Doesken, and J. Kleist, 1993: The relationship of drought frequency and duration to time scales. Proc. Eighth Conf. on Applied Climatology, Anaheim, CA, Amer. Meteor. Soc., 179-183.

McKinnon, K. A., A. Rhines, M. P. Tingley, and P. Huybers, 2016: Long-lead predictions of eastern United States hot days from Pacific sea surface temperatures. Nat. Geosci., 9, 389-394, doi:10.1038/ngeo2687.

Meehl, G. A., and C. Tebaldi, 2004: More intense, more frequent, and longer lasting heat waves in the 21st century. Science, $\mathbf{3 0 5}$, 994-997, doi:10.1126/science.1098704.

Menne, M. J., I. Durre, R. S. Vose, B. E. Gleason, and T. G. Houston, 2012: An overview of the global historical climatology network-daily database. J. Atmos. Oceanic Technol., 29, 897-910, doi:10.1175/JTECH-D-11-00103.1.

Miralles, D. G., A. J. Teuling, C. C. van Heerwaarden, and J. VilàGuerau de Arellano, 2014: Mega-heatwave temperatures due to combined soil desiccation and atmospheric heat accumulation. Nat. Geosci., 7, 345-349, doi:10.1038/ngeo2141.

Morak, S., G. C. Hegerl, and N. Christidis, 2013: Detectable changes in the frequency of temperature extremes. J. Climate, 26, 1561-1574, doi:10.1175/JCLI-D-11-00678.1.

Mueller, B., and S. I. Seneviratne, 2012: Hot days induced by precipitation deficits at the global scale. Proc. Natl. Acad. Sci. USA, 109, 12 398-12 403, doi:10.1073/pnas.1204330109.

Nairn, J., and R. Fawcett, 2013: Defining heatwaves: Heatwave defined as a heat-impact event servicing all community and business sectors in Australia. CAWCR Tech. Rep. 060, 84 pp. 
Oglesby, R. J., and D. J. Erickson, 1989: Soil moisture and the persistence of North American drought. J. Climate, 2, 1362-1380, doi:10.1175/1520-0442(1989)002<1362:SMATPO >2.0.CO;2.

Perkins, S. E., and L. V. Alexander, 2013: On the measurement of heat waves. J. Climate, 26, 4500-4517, doi:10.1175/ JCLI-D-12-00383.1.

- — - and J. R. Nairn, 2012: Increasing frequency, intensity and duration of observed global heatwaves and warm spells Geophys. Res. Lett., 39, L20714, doi:10.1029/2012GL053361.

—_, D. Argüeso, and C. J. White, 2015: Relationships between climate variability, soil moisture, and Australian heatwaves. J. Geophys. Res., 120, 8144-8164, doi:10.1002/ 2015JD023592.

Peterson, T. C., and Coauthors, 2013: Monitoring and understanding changes in heat waves, cold waves, floods, and droughts in the United States: State of knowledge. Bull. Amer. Meteor. Soc., 94, 821-834, doi:10.1175/BAMS-D-12-00066.1.

Pezza, A. B., P. van Rensch, and W. Cai, 2012: Severe heat waves in southern Australia: Synoptic climatology and large scale connections. Climate Dyn., 38, 209-224, doi:10.1007/ s00382-011-1016-2.

Saini, R., G. Wang, and J. S. Pal, 2016: Role of soil moisture feedback in the development of extreme summer drought and flood in the United States. J. Hydrometeor., 17, 2191-2207, doi:10.1175/JHM-D-15-0168.1.

Schubert, S. D., M. J. Suarez, P. J. Pegion, R. D. Koster, and J. T. Bacmeister, 2004a: On the cause of the 1930s Dust Bowl Science, 303, 1855-1859, doi:10.1126/science.1095048.
,,,--- and,$- 2004 \mathrm{~b}$ : Causes of long-term drought in the U.S. Great Plains. J. Climate, 17, 485-503, doi:10.1175/1520-0442(2004)017<0485:COLDIT>2.0.CO;2.

Seager, R., and M. Hoerling, 2014: Atmosphere and ocean origins of North American droughts. J. Climate, 27, 4581-4606, doi:10.1175/JCLI-D-13-00329.1.

Steffen, W., L. Hughes, and S. Perkins, 2014: Heatwaves: Hotter, longer, more often. Climate Council of Australia, 63 pp. [Available online at https://www.climatecouncil.org.au/heatwaves-report.]

Teng, H., G. Branstator, H. Wang, G. A. Meehl, and W. M. Washington, 2013: Probability of US heat waves affected by a subseasonal planetary wave pattern. Nat. Geosci., 6, 10561061, doi:10.1038/ngeo1988.

G. A. Meehl, and W. M. Washington, 2016: Projected intensification of subseasonal temperature variability and heat waves in the Great Plains. Geophys. Res. Lett., 43, 2165-2173, doi:10.1002/2015GL067574

Wang, H., S. Schubert, R. Koster, Y.-G. Ham, and M. Suarez, 2014: On the role of SST forcing in the 2011 and 2012 extreme U.S. heat and drought: A study in contrasts. J. Hydrometeor., 15, 1255-1273, doi:10.1175/JHM-D-13-069.1.

Yin, D., M. L. Roderick, G. Leech, F. Sun, and Y. Huang, 2014: The contribution of reduction in evaporative cooling to higher surface air temperatures during drought. Geophys. Res. Lett., 41, 7891-7897, doi:10.1002/2014GL062039.

Yu, J.-Y., and Y. Zou, 2013: The enhanced drying effect of CentralPacific El Niño on US winter. Environ. Res. Lett., 8, 014019, doi:10.1088/1748-9326/8/1/014019. 